\title{
Sea ice draft in the Weddell Sea, measured by upward looking sonars
}

\author{
A. Behrendt, W. Dierking, E. Fahrbach, and H. Witte \\ Alfred Wegener Institute for Polar and Marine Research, Bremerhaven, Germany \\ Correspondence to: A. Behrendt (axel.behrendt@awi.de)
}

Received: 25 July 2012 - Published in Earth Syst. Sci. Data Discuss.: 17 August 2012

Revised: 2 May 2013 - Accepted: 8 May 2013 - Published: 25 June 2013

\begin{abstract}
The presented database contains time-referenced sea ice draft values from upward looking sonar (ULS) measurements in the Weddell Sea, Antarctica. The sea ice draft data can be used to infer the thickness of the ice. They were collected during the period 1990-2008. In total, the database includes measurements from 13 locations in the Weddell Sea and was generated from more than 3.7 million measurements of sea ice draft. The files contain uncorrected raw drafts, corrected drafts and the basic parameters measured by the ULS. The measurement principle, the data processing procedure and the quality control are described in detail. To account for the unknown speed of sound in the water column above the ULS, two correction methods were applied to the draft data. The first method is based on defining a reference level from the identification of open water leads. The second method uses a model of sound speed in the oceanic mixed layer and is applied to ice draft in austral winter. Both methods are discussed and their accuracy is estimated. Finally, selected results of the processing are presented. The data can be downloaded from doi:10.1594/PANGAEA.785565.
\end{abstract}

\section{Introduction}

At its maximum extent Antarctic sea ice covers between $18 \times 10^{6}$ and $19 \times 10^{6} \mathrm{~km}^{2}$ of the Southern Ocean (Parkinson and Cavalieri, 2012). As the ice regulates the surface fluxes of water, heat and momentum between the ocean and the atmosphere, it has a profound influence on the global climate and the polar physical environment (Dieckmann and Hellmer, 2010). Antarctic sea ice formation and melt influences the water mass properties and thereby provides a forcing mechanism for the oceanic meridional overturning circulation (Kuhlbrodt et al., 2007). Furthermore, it acts as a nursery for krill larvae, hosts large numbers of micro-organisms (Thomas and Dieckmann, 2002) and provides a habitat for marine mammals and birds. As sea ice is affected by rising atmospheric and oceanic temperatures, it is also a sensitive indicator of global climate change (Lemke et al., 2007).

Variability and trends in southern sea ice extent and concentration have been widely studied, mainly by using data from satellite microwave imagery (e.g. Cavalieri and Parkinson, 2008), ship-based observations (e.g. Worby and Comiso, 2004), and historic reconstructions from whaling records (e.g. Ackley et al., 2003) or ice cores (e.g. Curran et al., 2003). Contrary to the Arctic, the thickness of Antarctic sea ice has not been surveyed by military nuclear submarines (Wadhams and Davis, 2000; Rothrock et al., 2008). Satellite altimetry over sea ice still suffers from uncertainties induced by the snow cover on the ice (Zwally et al., 2008). Other methods, like drilling, provide only snapshots of sea ice thickness and are often biased towards undeformed ice classes, as they are restricted to the accessible regions of the ice cover. The recently launched satellite CryoSat-2 has the capability to provide basin-scale information on sea ice thickness. However, it has so far not been applied to Antarctic sea ice. The use of moored ULS (upward looking sonar) instruments is yet the only source for information on the longterm development of Antarctic sea ice thickness in remote places of the sea ice cover. The Alfred Wegener Institute (AWI) has been running ULS instruments on 13 positions in the Southern Ocean in different years since 1990. They are deployed in austral summer for measurement periods of two or three years and provide a unique data set of Antarctic sea 


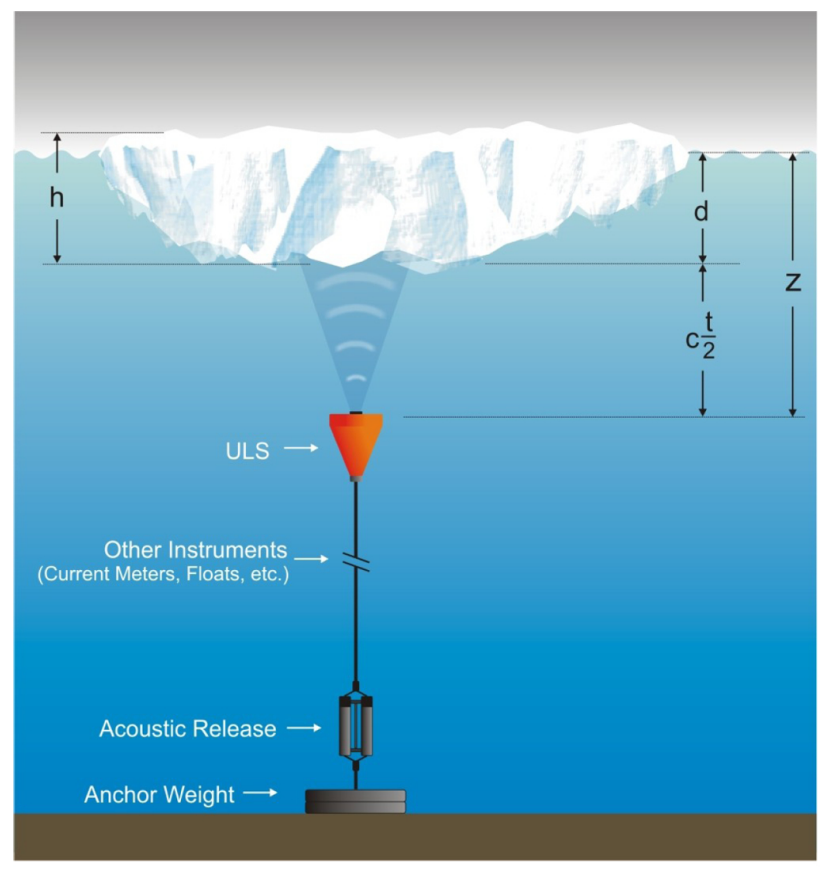

Figure 1. The ULS measurement principle. $d$ : sea ice draft, $z$ : instrument depth, $h$ : sea ice thickness, $c$ : sound velocity, $t$ : two-way travel time.

ice thickness. It is the largest array of ice profiling sonars in the Southern Ocean.

\section{Measurement principle}

The sonars are ES-300 series ULS instruments, manufactured by Christian Michelsen Research (CMR) in Norway. They transmit sound pulses of $300 \pm 15 \mathrm{kHz}$ towards the sea surface. These signals are primarily reflected either by the underside of the ice or, if no ice is present, by the water-air boundary. The two-way travel time of the signals is measured by the instrument and can be converted into a distance. When measuring reflections from open water, the calculated distance equals the instrument depth. When sea ice is present, the distance between ice bottom and ULS is obtained (Fig. 1). Subtracting this distance from the instrument depth yields the portion of the sea ice below the water level (ice draft). This information can be used to infer the total thickness of the ice, if its density and the snow load are known.

The ES-300 instruments are equipped with a pressure sensor to determine the instrument depth, a dual axis clinometer to measure the instrument tilt angle, and a temperature sensor. All sensors were calibrated before deployment and after recovery. Depending on the battery and data storage capacities of the instrument type, the ceramic transducer sends a burst of four pulses at time steps that were fixed between 2-15 min. In this way, the instruments can record several 100000 data cycles during one deployment period. At the same sampling rate, readings of pressure and tilt angle are taken. The detected travel times of the echoes are stored as 8 bit (software version 1.0) or 16-bit (software versions >1.0) digitised voltage values. Additionally, the envelope voltage $\left(V_{\text {env }}\right)$ of the signal is recorded. The envelope voltage is the logarithmically amplified echo amplitude (Strass, 1998) and can be regarded as a measure for the sound intensity of the reflecting interface. The instruments are attached on top of oceanographic moorings at depths of around $150 \mathrm{~m}$. This depth is a trade-off between the depth shallow enough to detect the reflected signals and to maintain a high measurement accuracy, and the depth needed to avoid the disturbing influence by surface gravity waves and possible damage by passing icebergs. The opening angle of the acoustic beam of $2.5^{\circ}$ at $-3 \mathrm{~dB}$ results in an ensonified surface window (footprint) of approximately $6-8 \mathrm{~m}$ in diameter.

\section{Data coverage and parameter measured}

Repository-Reference: doi:10.1594/PANGAEA.785565

Available at: http://doi.pangaea.de/10.1594/PANGAEA.785565

Coverage: $59-69.4^{\circ} \mathrm{S}, 52.1-0^{\circ} \mathrm{W}$

Location Name: Atlantic sector of the Southern Ocean

(Weddell Sea)

Date/Time Start: November 1990

Date/Time End: March 2008

The first six ULS instruments were deployed in November 1990 on a transect spanning the Weddell Sea from Kapp Norvegia to Joinville Island at the tip of the Antarctic Peninsula (Fig. 2). They were recovered and redeployed in 1992 and acquired data until the next recovery in 1995. Only half of the maximum achievable data volume was obtained, due to flooded instruments or lost moorings. Furthermore, the data output of the remaining instruments was reduced after quality controls. The success rate of this first phase of data acquisitions was $86 \%$. From 1996 on, the measurements were concentrated on the prime meridian, with six ULS instruments positioned from around 59 degrees southern latitude to a location on the continental slope off the Antarctic coast. Additionally, AWI-207 continued measuring at the Antarctic Peninsula in the years 1996 and 1997 and from 2005 to 2008, and AWI-206 measured in 1996 and 1997. The failure rate due to flooded instruments or lost moorings during the period 1996-2008 was about one third, and the usable data volume of the remaining instruments was $78 \%$. Most of the data gaps on the prime meridian (Fig. 2) are due to instrument failure. The data record length for individual files ranges from less than a year to more than two years. All moorings equipped with ULS instruments are deployed at fixed positions and in water depths of more than $900 \mathrm{~m}$, some of them in depths exceeding $4500 \mathrm{~m}$. The mooring positions, deployment periods and record periods are summarised in Table 5. 


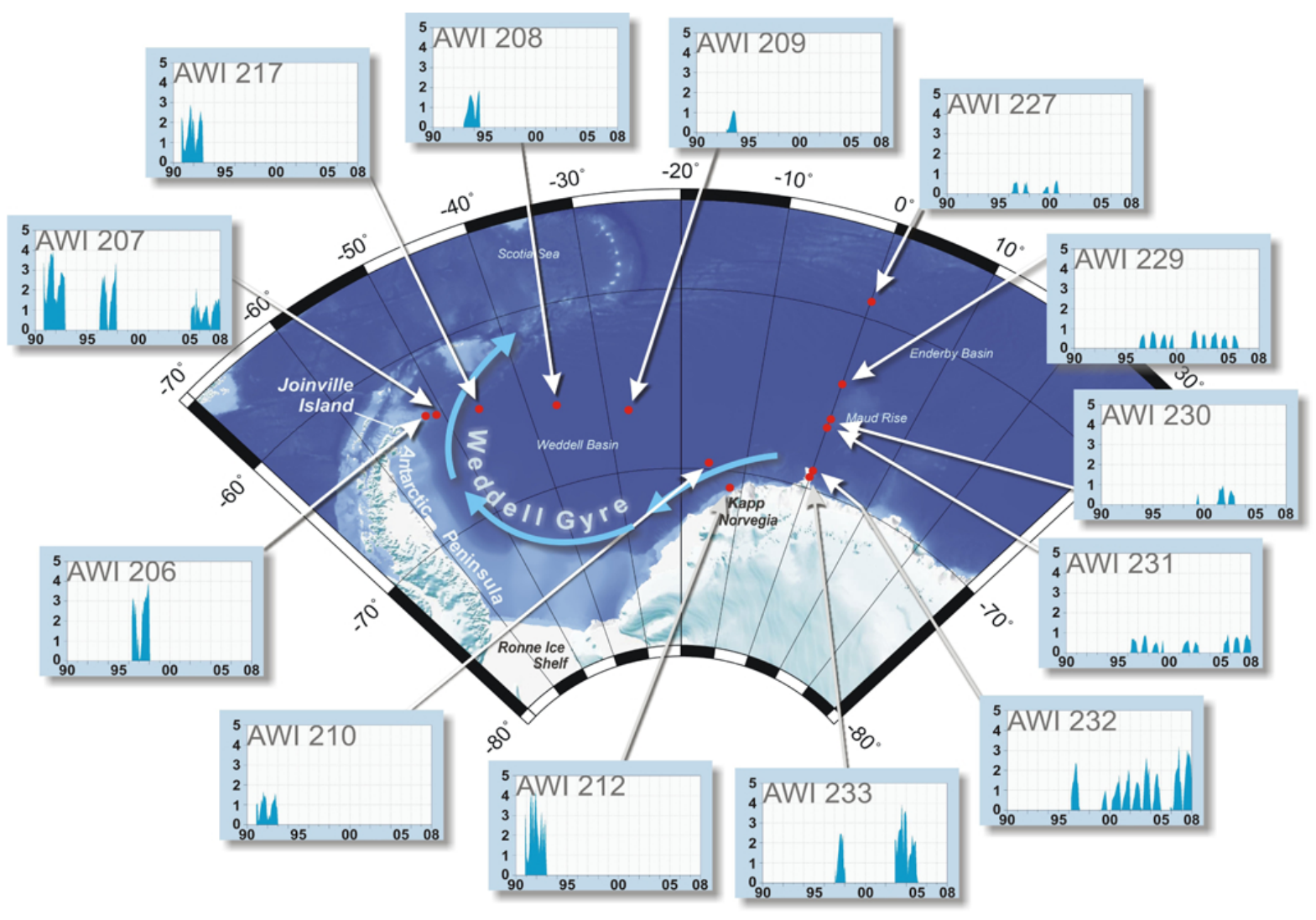

Figure 2. The AWI ULS array in the Atlantic sector of the Southern Ocean. The diagrams show monthly mean values of sea ice draft from 0 to $5 \mathrm{~m}$ (y-axis), spanning the period from January 1990 to December 2007.

The first measurements in the western and central Weddell Sea were mainly aimed at estimating volume flux budgets of sea ice (e.g. Harms et al., 2001) and water masses in the Weddell Gyre. The measurements were then shifted to the prime meridian for logistical reasons and to investigate a possible recurrence of the Weddell Polynya, which was observed by satellites in the mid-1970s.

In 2008, sonars were deployed on the positions AWI-206, AWI-207, AWI-208, AWI-229 and AWI-232, extending their records into the year 2011. Their raw data will be processed in the near future.

\section{Data processing}

The raw 8/16-bit data are stored in ASCII files that include the two-way travel time for each of the four signals in a single burst (for software version 1.0 only the two most similar signals), their envelope voltages, temperature, pressure, tilt of the instrument in $x$ and $y$ directions, and date/time.

The pressure measured by the ULS is always the sum of the hydrostatic and the atmospheric pressure. It is therefore corrected by pressure data from atmospheric model reanalysis of the European Centre for Medium-Range Weather Forecasts (ECMWF). The data are provided on a $1.125^{\circ}$ grid and were processed especially for AWI. Not correcting for atmospheric pressure would cause an error in the ice draft of about $10 \mathrm{~m}$. Another serious error source is the variation of the vertical mean sound speed in the water column above the ULS. The sound speed profiles depend on temperature and salinity. For example, if a colder water mass drifted through the vertical path of the ULS sound signals, it would lower the thermocline and thereby reduce the vertical mean temperature. This in turn would reduce the vertical mean sound speed. Not correcting for sound speed would cause an ice draft bias of up to $60 \mathrm{~cm}$. Measured density profiles, from which the sound speed can be calculated, are not available at the required temporal resolution. Therefore, a fixed value is assumed for the mean sound speed $\left(1442 \mathrm{~m} \mathrm{~s}^{-1}\right)$ and density $\left(1027 \mathrm{~kg} \mathrm{~m}^{-3}\right)$. The draft calculated in this way is called pseudo draft. The natural variations of the true sound speed and density in the ocean result in a varying offset between the zero line in the pseudo draft (i.e. $0 \mathrm{~m}$ draft) and the true zero level (i.e. the sea surface). The correction of this error is based on the identification of open water areas in the data series at which the spatially varying offset of the pseudo draft can be determined. A comprehensive discussion of error sources and a possible way of correcting the zero level is also provided by Melling et al. (1995). 


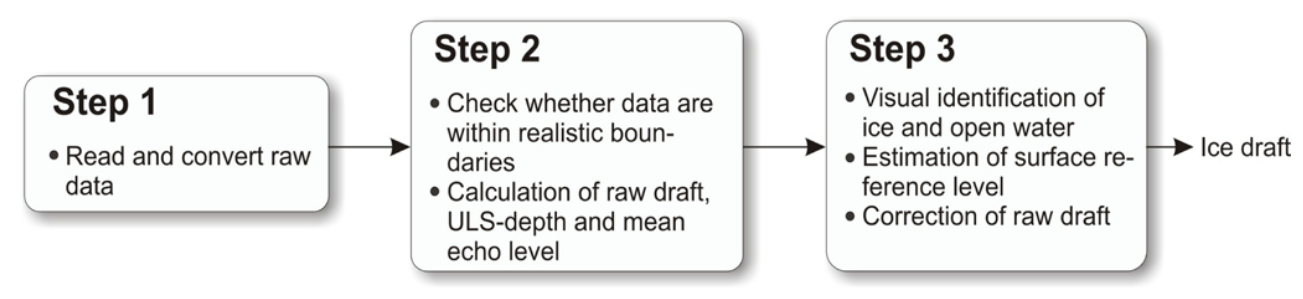

Figure 3. The ULS data processing chain.

Table 1. Quantities contained in the data files.

\begin{tabular}{lllllll}
\hline Column & 1 & 2 & 3 & 4 & 5 & 6 \\
\hline Quantity & date/time & depth & $\begin{array}{l}\text { water } \\
\text { pressure }\end{array}$ & $\begin{array}{l}\text { pseudo } \\
\text { draft }\end{array}$ & $\begin{array}{l}\text { draft (zero line } \\
\text { correction) }\end{array}$ & $\begin{array}{l}\text { flag (zero line } \\
\text { correction) }\end{array}$ \\
\hline Unit & $\begin{array}{l}\text { yyyy-mm- } \\
\text { ddThh:mm }\end{array}$ & $\mathrm{m}$ & dbar & $\mathrm{m}$ & $\mathrm{m}$ & \\
\hline Column & 7 & 8 & 9 & 10 & 11 & \\
\hline Quantity & $\begin{array}{l}\text { draft (model } \\
\text { correction) }\end{array}$ & $\begin{array}{l}\text { flag (model } \\
\text { correction) }\end{array}$ & $\begin{array}{llll}\text { time of } \\
\text { flight }\end{array}$ & tilt angle & $\begin{array}{l}\text { water tempe- } \\
\text { rature }\end{array}$ & \\
\hline Unit & $\mathrm{m}$ & & $\mathrm{s}$ & $\circ$ & ${ }^{\circ} \mathrm{C}$ & \\
\hline
\end{tabular}
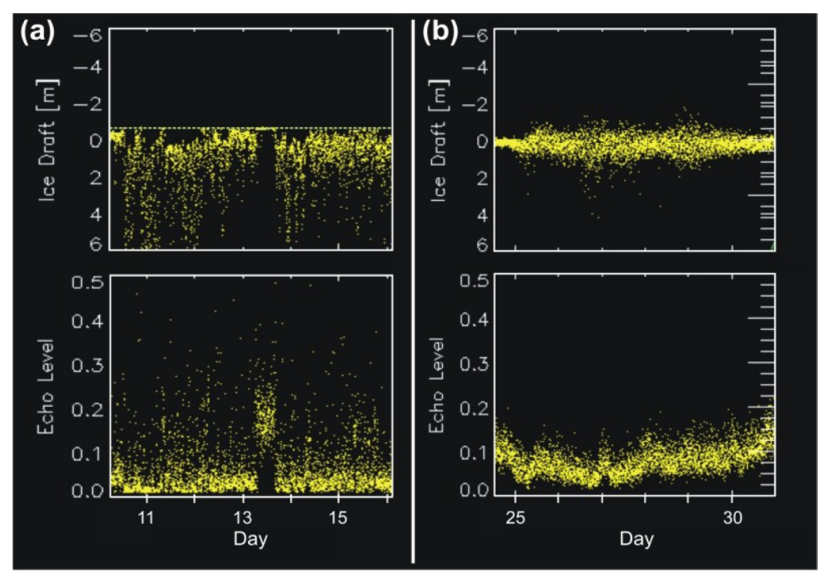

Figure 4. (a) Sea ice pseudo draft (upper panel) and echo level (lower panel) from AWI 232-8 for an ice period in December 2006. Every dot stands for one draft measurement (sample rate: $2 \mathrm{~min}$ ). The true zero level is indicated as dashed line at about $-0.7 \mathrm{~m}$. Both the draft data and the echo level display a short period of open water on day 13. (b) Typical appearance of an open water period from AWI 232-8 in January 2008.

Our data processing system developed at AWI includes three basic steps (Fig. 3) and works as follows:

- In step one, the raw data are read and converted into physical quantities. The conversion of the decimal values into engineering units is made according to the formulae given in the manual of Lothe and Baker (2000).
- In step two, the programme checks whether the data are within realistic boundaries and calculates the pseudo draft. Single data are rejected if: temperature $<-10{ }^{\circ} \mathrm{C}$ or $>10^{\circ} \mathrm{C}$, pressure $>200 \mathrm{dbar}$ or $<20 \mathrm{dbar}$, tilt angle $>5^{\circ}$, draft $>30 \mathrm{~m}$ or $<-10 \mathrm{~m}$. The data analyst visually identifies longer open water periods (at this step not including leads). If accepted, these data sequences are automatically set to zero draft. The detection of larger open water areas in step two is aided by the auxiliary variable $V_{\text {env }}$, from which the echo level (Fig. 4) can be derived. The echo level is higher for sound reflections at the water-air interface than for reflections at the icewater interface. This is due to the stronger contrast in the acoustic impedances of water and air compared to water and ice (Melling, 1998). Due to increased scattering by gravity waves, the echo level is also reduced for open water surfaces disturbed by wind action (Fig. 4). Our processing software therefore additionally displays ECMWF wind speeds to reduce the risk of misinterpretation. Draft signals emerging from an ice surface also have a characteristic shape in the pseudo draft plots, which can in many cases be easily distinguished from open water signals (Fig. 4). When the sonar measures open water, the echoes are almost symmetrically scattered around the zero level by surface gravity waves (Fig. 4). This is most obvious when the sampling rate is high and the open water areas are large. The zero level can then be assumed to lie roughly in the centre of the echo distribution. The operator also has the possibility to reject obviously erroneous data that occur, e.g. when 
the ULS is depressed to large depths by a passing iceberg, tides or ocean currents.

- To correct the offset in the pseudo draft in step three, smaller open water areas (i.e. leads) are detected automatically within periods of ice coverage in pre-defined windows of 24-96h width, depending on the sample rate of the ULS. Within these windows the algorithm finds the median of the $5 \%$ smallest pseudo draft values. Data points $5 \mathrm{~cm}$ below and above the median are then flagged as tie points for the correction line. The line is then linearly interpolated between all tie points over the full data record. The interpolated zero lines for ice are found to be in good agreement with the centre of open water echo distributions adjacent to periods of ice coverage. The data analyst has the possibility to manually correct the interpolated line, if some leads were not captured by the search algorithm. Nevertheless, the visual detection of narrow open water leads requires some experience. Not all records of the echo level have the required quality to distinguish between ice and narrow leads (see below). Based on the interpolated zero line, the full draft record is corrected by setting the line to zero draft.

Since the processing method relies on the experience of the data analyst, it has a certain degree of subjectivity. Especially for periods of ice-water transition in autumn and spring the manual zero-level correction is sometimes difficult and requires great care. Studies about sound scattering effects on sea ice showed that the surface scattering coefficient does not change abruptly between open water and the first appearance of sea ice (Melling, 1998). In case of thin ice coverage the position of the reference level is therefore not always clear and may differ between data processed by different analysts. In an experiment, the results obtained by two analysts were compared, and the mean rms-difference of the ice draft was found to be $11 \mathrm{~cm}$ for the period December-January. For September-November it is $9 \mathrm{~cm}$, and for March-May and June-August $6 \mathrm{~cm}$ and $5.5 \mathrm{~cm}$, respectively. The differences are therefore largest in the summer season. Finally, identification flags are added to each recorded draft value: 0 for open water, $l$ for ice and 2 for thin ice-open water.

Empty cells in the data files correspond to rejected/erroneous data. Values flagged with 2 are ice drafts smaller than $5 \mathrm{~cm}$. This flag is set because of the possible bias introduced by the identification of tie points for the correction-line (see step three of the data processing). The quantities contained in the different file types are summarised in Table 1. The depth (column 2) was calculated from the first term of the ULS equation (see next section) using atmospheric pressure from ECMWF reanalysis. The pseudo draft (column 4) is the uncorrected raw draft calculated from the full ULS equation using ECMWF pressure and all parameters measured by the ULS. Column 5 contains the corrected draft using the zero-line approach. To account for the differ-
Table 2. Absolute values used for the sensitivity study.

\begin{tabular}{|c|c|}
\hline \multicolumn{2}{|c|}{ Instrumental parameters } \\
\hline $\begin{array}{l}\text { travel time } \\
\text { pressure } \\
\text { tilt angle }\end{array}$ & $\begin{array}{l}t=0.205275 \mathrm{~s} \\
p=16.1347 \mathrm{bar} \\
\alpha=0^{\circ}\end{array}$ \\
\hline \multicolumn{2}{|c|}{ Geophysical parameters } \\
\hline $\begin{array}{l}\text { acceleration of gravity } \\
\text { sound speed } \\
\text { atmospheric pressure } \\
\text { water density }\end{array}$ & $\begin{array}{l}g=9.8231 \mathrm{~m} \mathrm{~s}^{-2} \\
\bar{c}=1442 \mathrm{~m} \mathrm{~s}^{-1} \\
p_{\mathrm{a}}=990 \mathrm{hPa} \\
\bar{\rho}=1027.8 \mathrm{~kg} \mathrm{~m}^{-3}\end{array}$ \\
\hline
\end{tabular}

ences in the results of two analysts, the results were averaged. The ice draft in column 7 is the corrected draft using the sound speed model (see Sect. 7) for the winter months. The spring and autumn months contain the same ice draft as in column 5 . The water temperature (column 11) was used for the sound speed model. We provide as well the completely unprocessed raw data of pressure (column 3), signal travel time (column 9) and tilt angle (column 10) from the ULS to allow future users the application of their own correction algorithms, since we recognise that correction methods require to some extent subjective decisions, which might change with increasing knowledge on the instruments and sea ice properties.

At AWI 206-4 and AWI 227-3 the pressure sensors failed completely. The drafts of these two instruments were therefore taken from the study of Harms et al. (2001). They were processed with a different procedure which also allowed for a simple interactive correction of the data. However, this method was technically not as sophisticated as the one described above. The lacking pressure data of AWI 206-4 and AWI 227-3 were replaced by the pressure measurements of the instrument that was attached to the mooring below the ULS. Since the recording intervals of the two instruments differed significantly, interpolated pressure time series had to be used. The data of AWI 206-4 and AWI 227-3 therefore have to be considered with care.

\section{Sensitivity study}

The ULS equation, from which the ice draft is derived, consists of a term for computing the instrument depth and a term from which the distance between the instrument and the ice bottom is obtained (Fig. 1):

$d=\frac{p-p_{\mathrm{a}}}{g \rho}-\frac{1}{2} c t \cos (\alpha)$.

Here, $d$ is the draft, $p$ the measured ambient pressure, $p_{\text {a }}$ the atmospheric pressure, $g$ the gravitational acceleration on Earth's surface, $\rho$ the water density, $c$ the average speed of sound in the water column, $t$ the measured sound pulse travel 

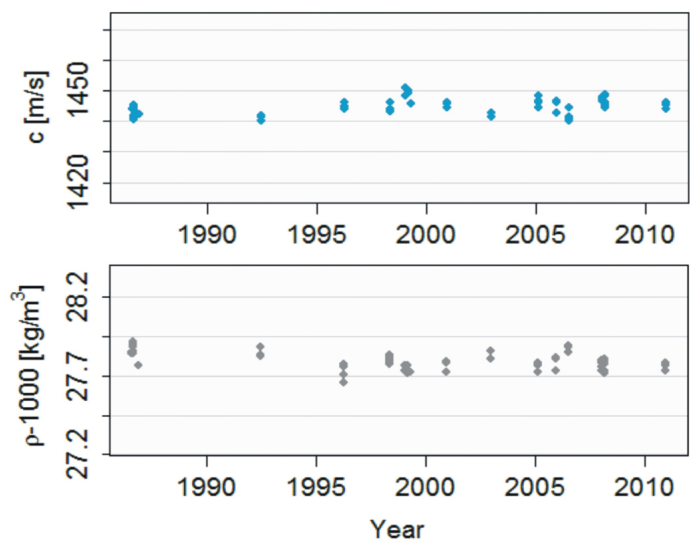

Figure 5. Vertical mean sound velocity (upper panel) and density (lower panel), calculated from CTD (conductivity, temperature, depth) measurements for the upper $150 \mathrm{~m}$ on the position of AWI231. The $y$-axes span the range $\pm 2 \%$ of the mean value of the respective data.

time (two way) and $\alpha$ the tilt of the instrument. The variables on the right-hand side of Eq. (1) can be divided into instrument parameters $(p, t, \alpha)$ and geophysical parameters $\left(g, c, p_{\mathrm{a}}, \rho\right)$.

To estimate the theoretical contribution to the uncertainty by each variable, one can use realistic estimates of all variables in Eq. (1) and alter each value by its uncertainty. The absolute values used for the sensitivity study are shown in Table 2. The parameters $p, p_{\mathrm{a}}, g$ and $\rho$ are chosen in such a way that they correspond to a ULS depth of $150 \mathrm{~m}$. The measured signal travel time is valid for an ice draft of $2 \mathrm{~m}$. The influence of each uncertainty on the ice draft was estimated with the signal travel time given above, and altering step by step each absolute value by its uncertainty. First, the instrumental parameters are considered: the uncertainty in the time measurement is $\Delta t= \pm 13 \mu$ s for the instrument type ES-300 $\mathrm{V}$ and $\Delta t= \pm 4.3 \mu \mathrm{s}$ for the instrument types ES-300 VI and VIII. These uncertainties would cause a change in ice draft of less than $1 \mathrm{~cm}$. The uncertainty of the tilt sensor is $\Delta \alpha= \pm 1^{\circ}$, which translates into $2-3 \mathrm{~cm}$ ice draft. The overall error of the pressure sensor results from contributions that depend on the measured pressure and contributions that are independent of pressure. Both contributions include a temperature coefficient, statistical errors and long-term stability (drift) (Honeywell, 2004). The most probable overall error in the pressure sensor calculated from the instrument specifications and considering a drift over one year is $\Delta p= \pm 0.12 \mathrm{dbar}$, which translates into a $12 \mathrm{~cm}$ ice draft ( $24 \mathrm{~cm}$ for two years). The uncertainties in the pressure sensor therefore dominate the uncertainties of the instrumental parameters.

Next, the geophysical variables are considered: the uncertainty in the ECMWF pressure $\Delta p_{\mathrm{a}}$ is taken from the study of King (2003). The value $\Delta p_{\mathrm{a}}= \pm 1 \mathrm{hPa}$ stands for the average standard deviation of the differences between ECMWF pressure and the pressure measured by sensors on ice floes in the Bellinghausen Sea and is assumed to be a reasonable estimate for the Weddell Sea as well. It would result in a change in ice draft of about $1 \mathrm{~cm}$. The latitude-dependent acceleration of gravity is calculated after Roedel (1994). The latitude of the mooring positions is very precisely known, and the uncertainty in $g$ can be neglected. The values $\Delta \rho$ and $\Delta c$ can be estimated from CTD (conductivity, temperature, depth) measurements. The standard deviations of the plotted values in Fig. 5 are $\Delta \rho=0.05 \mathrm{~kg} \mathrm{~m}^{-3}$ and $\Delta c=2.6 \mathrm{~m} \mathrm{~s}^{-1}$. These values can be used to alter the absolute values, like in the examples above. An uncertainty of $0.05 \mathrm{~kg} \mathrm{~m}^{-3}$ in the density would cause an error in the ice draft of less than $1 \mathrm{~cm}$. The uncertainty in the sound speed of $2.6 \mathrm{~m} \mathrm{~s}^{-1}$ on the contrary would cause an ice draft error of $27 \mathrm{~cm}$. The value of $\Delta c$ can therefore be assumed to dominate the uncertainties of the geophysical variables. The uncertainties of density and sound speed have to be considered if the model of sound speed is used to correct the raw draft values (see below).

In a perfect scenario, the zero-line correction method should eliminate all the discussed errors. The extent to which this is true is discussed in the following section.

\section{Ice draft error estimation}

In this section, the error that remains after the zero-level correction will be estimated. Here, we focus on periods of ice coverage in autumn and spring, when the number of open water areas and leads is relatively high. As described above, the operator identifies longer periods of open water above the ULS during the processing of the data. Smaller open water features, such as leads, are in most cases detected as draft minima by the interpolation algorithm. However, the algorithm does not capture every small crack in the ice. These remaining cracks and leads can be identified and used to estimate the error of the zero-level correction by investigating the statistical distribution of the ice draft that remains after the correction.

The identification of cracks and leads is aided by the echo level, which is usually much higher for water. The discrimination between echoes from ice and water depends on the sample rate of the instrument. Only those instruments with periods of 2-4 min were found to be suitable for the procedure. The number of usable records was further reduced, as the quality of the echo level turned out to be crucially dependent on the sensitivity and gain settings of the ULS receiver. Finally, only six data sets (AWI 207-6, AWI 227-4, AWI 2317, AWI 232-6, AWI 232-8 and AWI 233-2) were found to be useful for a reliable ice/water discrimination.

The detection algorithm was programmed in such a way that leads are flagged when the echo level crosses a predefined threshold. Typical echo levels of open water can be obtained from the measurements in austral summer, in periods when the wind speeds are low and the sea surface is 

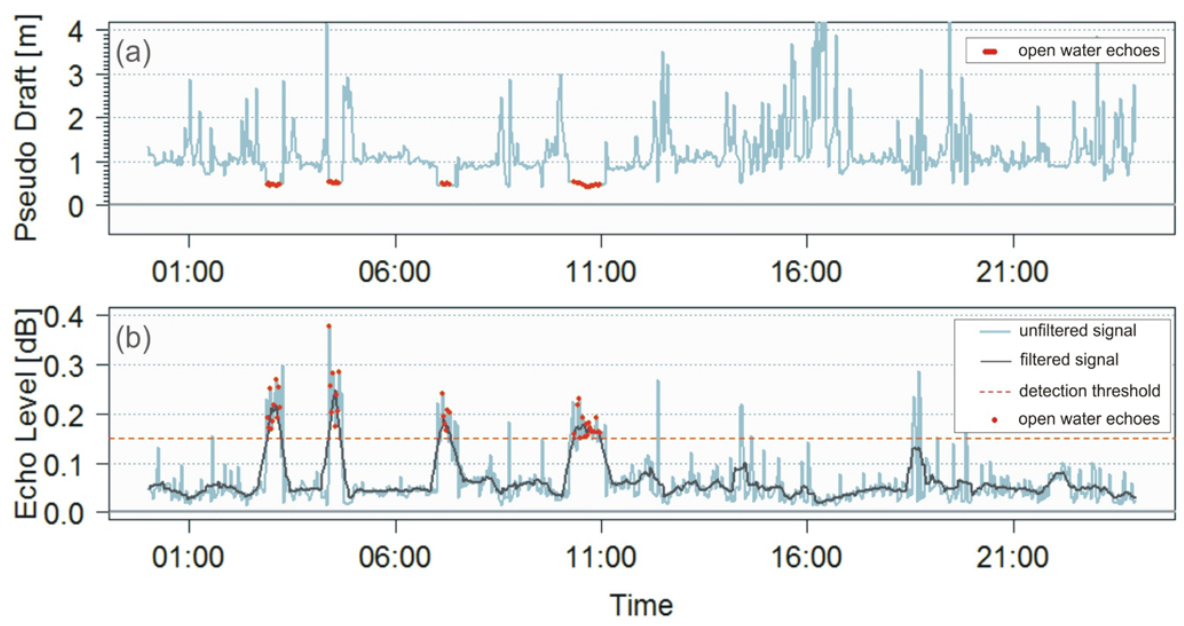

Figure 6. (a) Pseudo draft of AWI 231-7 on 8 November 2007. (b) Echo level of the same period.

calm. As the echo level is highly variable and not every single peak above the threshold represents open water, the echo signal was filtered as a 10-points running mean. This guarantees that the threshold is passed only by those signals that on average remain high for a longer time period, which is typical for leads. Within these time windows the times of open water were then defined as the points of the unfiltered echo level that lie above the echo threshold (Fig. 6). The performance of this method can be assessed with the respective pseudo draft plot. Leads within the ice appear as rectangularshaped gaps in the draft record. Intervals with strongly winddisturbed open water were excluded to avoid a bias of the surface level offset. Leads that were correctly captured by the search algorithm - i.e. the tie points of the interpolated zero line - have zero draft. Thus, their error is zero. The resulting elevation distribution of the leads that were not detected is approximately Gaussian shaped. In this time series the statistical open water draft mode was detected similarly to the method of Strass (1998): single modes were detected for leads observed long enough to remove the noise resulting from short surface gravity waves. The final mode was then calculated as the mean of the open water draft modes from those leads in the six data sets that were identified by their echo level but not detected by the search algorithm or the operator. The mean open water draft mode found in this way is $4 \mathrm{~cm}$. The standard deviation of the mean open water draft mode is $\pm 6 \mathrm{~cm}$. The mode represents a bias, whereas the standard deviation represents the dispersion (precision) of the corrected draft data around the location of undetected leads. The overall accuracy is then calculated as the root mean square (rms) error, which accounts for both types of errors (Hauck et al., 2008). The accuracy found in this way is about $\pm 7 \mathrm{~cm}$.

Another problem is that tie points can mistakenly or on purpose be selected within thin ice. For spring and autumn, the tie points selected by the search algorithm could be shown to represent open water by assessing their echo level. In winter, the algorithm sometimes uses ice because of the lack of leads. This problem is further discussed below. Note also that the error is a local estimate which is valid for leads that were not detected.

To estimate the error of the full data record one also has to consider all leads that were correctly detected for the zeroline interpolation by the processing algorithm. About $55 \%$ of all leads identified by the echo level were found to be detected by the search algorithm. These detected leads have zero mean and standard deviation. If the above procedure is repeated, the mean open water draft mode is reduced to $2 \mathrm{~cm}$ and the standard deviation of the mean open water draft mode to $\pm 4.5 \mathrm{~cm}$. The corresponding rms-error is $\pm 5 \mathrm{~cm}$. One has to be aware that the calculation is based on only 6 out of 33 of our data sets and therefore may not reflect the accuracy of all available data. However, the six data sets used for the calculation were acquired from 59 to $69^{\circ} \mathrm{S}$ latitude on the prime meridian and include a record from the Antarctic Peninsula, thus representing different ice regimes. Therefore, they can be regarded as a reasonable estimate for the remaining data sets as well. Melling and Riedel (1995) and Melling et al. (1995) deployed ULS instruments for 5-6 months in the Arctic and fitted curves through the available open water points. The fitting error of these curves was $\pm 2 \mathrm{~cm}$ and represents the precision of measurement. For the accuracy the authors give a value of $\pm 5 \mathrm{~cm}$ which is equal to the value presented here.

However, an additional problem arises if no leads are present over long periods in winter. In these cases the zeroline interpolation is biased. If no leads are present for a longer period, the search algorithm picks the thinnest ice as minima and incorporates it into the zero-line interpolation. The bias therefore depends on the mean thickness of the thin ice. The problem can be illustrated by calculating the ice draft for times when the true sound speed profile in the water column 

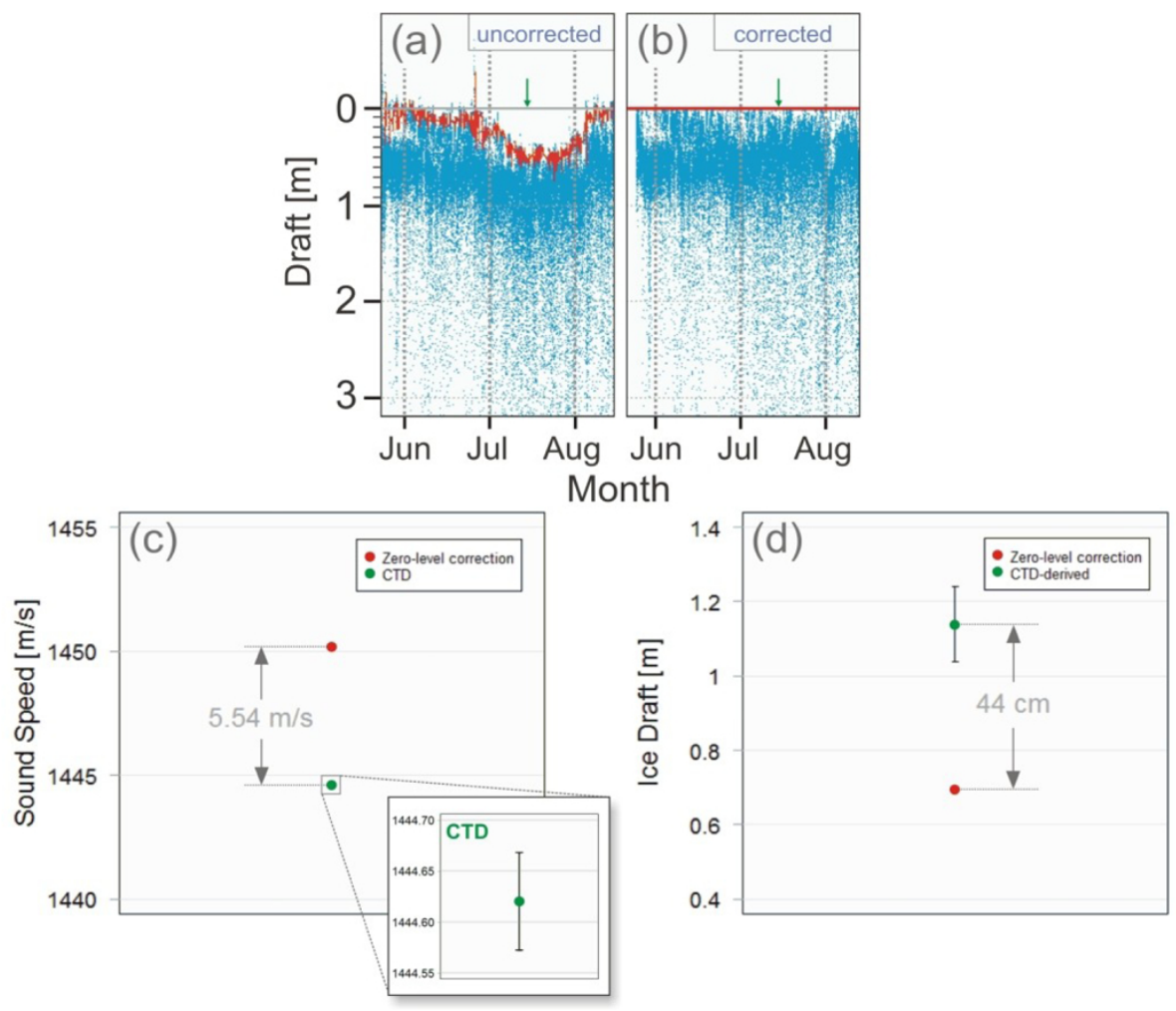

Figure 7. (a) Pseudo draft of AWI 231-7 in winter 2006 (sample rate: $4 \mathrm{~min}$, ULS depth: $125 \mathrm{~m}$ ). The red line depicts the interpolated zero line through ice draft minima. The green arrow marks the time of CTD measurement. (b) Corrected ice draft with the interpolated line levelled to zero draft. (c) Mean sound speed calculated from a CTD measurement on 13 July 2006, 20:03:00, and mean sound speed that would be needed to obtain the corrected ice draft in $(\mathbf{b})$ at the same time with the respective ULS parameters. The error bars on the sound velocity were obtained by calculating an error propagation for the sound speed equation of Mackenzie (1981) and using salinity, temperature and depth from CTD. (d) Corrected ice draft on 13 July 2006 at the time of the CTD measurement, and ice draft calculated with the CTD-derived sound speed. The error bars of the ice draft were obtained through error propagation, using the uncertainty $\Delta c$ from the CTD sound speed in (c) and neglecting $\Delta \rho$.

is known from CTD measurements. The extreme example in Fig. 7 shows that the draft calculated from CTD measurements in winter 2006 is more than $40 \mathrm{~cm}$ larger than the draft obtained by zero-level correction. This is due to the false interpretation of draft minima as water in the interpolated zero line. As this error is expected to appear only in the winter months, we propose an alternative correction method for winter ice drafts, which is based on a sound speed model.

\section{Sound speed model}

The model basically approximates the temperature profile in the winter mixed layer and translates it into a sound speed profile. It is based on the assumption that the temperature profile in winter can be approximated by a hyperbolic tangent function (Strass, 1998):

$T(z)=T_{\mathrm{uls}}+0.5\left(T_{\mathrm{sst}}-T_{\mathrm{uls}}\right)[1-\tanh (s(z-h))]$,

where $T_{\text {sst }}$ is the sea surface temperature, $T_{\text {uls }}$ is the temperature at the ULS depth, $z$ is the depth, and $s$ and $h$ the steepness and the depth of the inflection point, respectively. The depth of this point corresponds to the depth of the mixed layer. The sea surface temperature is set to a constant value of $-1.8^{\circ} \mathrm{C}$, since only the winter months are considered here. In fact, CTD measurements on the mooring positions in winter showed that the temperature of the surface layer - at least the upper $50 \mathrm{~m}$ - is always at the freezing point. The lower bound is given by the temperature record of the ULS. The steepness $s$ does not significantly alter the vertical mean sound velocity. It is set to a constant value of 0.05 , which was found to match most of the CTD profiles well. The depth of the inflection point on the contrary does alter the vertical mean sound velocity significantly. For a ULS at $150 \mathrm{~m}$ and $T_{\mathrm{uls}}=1.2^{\circ} \mathrm{C}$, a change in depth of the inflection point from 40 to $80 \mathrm{~m}$ would alter the mean sound velocity between the surface and the ULS by about $3.8 \mathrm{~m} \mathrm{~s}^{-1}$. Keeping the measured travel time of the sonar signal constant, this would alter the calculated ice draft by about $40 \mathrm{~cm}$. The depth of the inflection point can be derived from $T_{\text {uls }}$. For most of the ULS data we found a significant negative correlation between $h$ and $T_{\mathrm{uls}}$ 
from CTD observations at the respective mooring positions. If $T_{\text {uls }}=-1.8^{\circ} \mathrm{C}$, the temperature profile is constant from the surface to the ULS depth. Depth oscillations of the ULS instruments due to mooring motions from ocean currents can amount up to $60 \mathrm{~m}$. As this affects the vertical mean sound speed, the depth changes of the ULS are also considered in the model.

We investigated more than 400 CTD profiles measured in the Weddell Sea during the years 1986-2010 for correlation between temperature and sound speed. The measurements were made close to the ULS-mooring sites within a radius of 50 nautical miles. The correlation coefficient between the two quantities is always very close to one. The temperature profile can therefore directly be translated into a sound speed profile by a linear fit to the scatterplot of temperature and sound speed. Each time a sonar echo is received (every 2$15 \mathrm{~min}$ ) one vertical mean sound speed is calculated from the profiles. The path between sea ice and ULS consists of different layers, each having different temperature and salinity that affect the sound speed. For calculating the average value of sound speed from model or CTD profiles, we assume that all layers have the same thickness. Therefore, the average sound velocity is obtained by the harmonic mean of the individual velocities. In the following, all vertical means of sound speed from the model or CTD are calculated as harmonic means. If an ice draft of e.g. $5 \mathrm{~m}$ occurs, the upper $5 \mathrm{~m}$ of the profile would have to be excluded from the average. But as the ice draft is calculated from the sound speed and therefore not known before, the influence of the ice thickness on the calculation of the mean is ignored. In the case of $5 \mathrm{~m}$ ice draft it would cause an ice draft error of about $2 \mathrm{~cm}$. Most of the encountered ice drafts are considerably smaller than $5 \mathrm{~m}$, and the error can be assumed to be negligible.

The calculated sound speeds were used to correct the pseudo draft of each ULS file. The mean rms-difference in the winter months between data corrected by zero-line interpolation and the sound speed model is about $27 \mathrm{~cm}$ (Table 3 ). However, the comparably high rms-differences of AWI 2316, AWI 232-1, AWI 232-8 and AWI 233-2 suggest that the quality of the sound speed model is limited at times.

The described correction could not be applied to ULS instruments on the position of AWI-229, as the variations of the thermocline depth (inflection point) were found to be strongly independent of $T_{\mathrm{uls}}$ at times. This behaviour seems to originate from oceanic processes, because the position 229 lies in an oceanic frontal zone, where strong north-south gradients in the salinity of the surface waters and also in the eastward geostrophic transport are observed (Whitworth III and Nowlin Jr., 1987). In these frontal zones mesoscale eddy activity enhances the cross-frontal exchange (Whitworth III and Nowlin Jr., 1987), which might destroy the correlation between $T_{\text {uls }}$ and $h$ through entrainment of water from further north or south into the upper water layers.
Table 3. RMS-deviations of ice draft in the winter months of data corrected by two different methods.

\begin{tabular}{llll}
\hline AWI 207-2 & $17 \mathrm{~cm}$ & AWI 231-2 & $24 \mathrm{~cm}$ \\
AWI 207-4 & $32 \mathrm{~cm}$ & AWI 231-3 & $15 \mathrm{~cm}$ \\
AWI 207-6 & $20 \mathrm{~cm}$ & AWI 231-4 & $34 \mathrm{~cm}$ \\
AWI 208-3 & $22 \mathrm{~cm}$ & AWI 231-6 & $52 \mathrm{~cm}$ \\
AWI 209-3 & $19 \mathrm{~cm}$ & AWI 231-7 & $28 \mathrm{~cm}$ \\
AWI 210-2 & $21 \mathrm{~cm}$ & AWI 232-1 & $46 \mathrm{~cm}$ \\
AWI 212-2 & $19 \mathrm{~cm}$ & AWI 232-4 & $29 \mathrm{~cm}$ \\
AWI 217-1 & $18 \mathrm{~cm}$ & AWI 232-5 & $33 \mathrm{~cm}$ \\
AWI 227-4 & $23 \mathrm{~cm}$ & AWI 232-6 & $34 \mathrm{~cm}$ \\
AWI 227-6 & $21 \mathrm{~cm}$ & AWI 232-8 & $42 \mathrm{~cm}$ \\
AWI 230-3 & $39 \mathrm{~cm}$ & AWI 233-2 & $45 \mathrm{~cm}$ \\
AWI 231-1 & $19 \mathrm{~cm}$ & AWI 233-6 & $26 \mathrm{~cm}$ \\
\hline
\end{tabular}

\section{Pressure sensor drift}

The zero-line correction method corrects the error contribution of drifts in the pressure sensor. However, the sound speed correction does not account for pressure drift. We observed drifts that were responsible for an apparent change in ice draft of almost $0.5 \mathrm{~m}$ within eight months, which is much larger than given in the instrument specifications of the pressure sensor. The drift could be easily identified only in those data sets in which the sound speed profile is linear throughout the winter months. This applies only to ULS instruments moored at depths less than $120 \mathrm{~m}$ or on the continental slope where the stratification in the upper layers is weaker. The constant difference between the vertical mean sound speed and the preset sound speed of $1442 \mathrm{~m} \mathrm{~s}^{-1}$ used to calculate the pseudo draft results in a very clear and straight zero line in the ice draft. This enables the visual correction of the pressure drift (Fig. 10). However, pressure drift was not found in all data sets.

For finding indications of depth changes of the ULS instruments, the signal travel time was used. Contrary to the pressure sensor, the clock measuring the signal travel time is not expected to show a significant drift. A linear fit to the signal travel times of the whole period is therefore assumed to display the true change in depth of the instrument. In most cases the trend in time was negative, i.e. the sonars tend to rise by a few metres. This upward movement may result from twisted mooring lines that slowly stretch during the measuring period. In the next step it was checked to what extent a linear trend in pressure explains the trend in time. The pressure record is always a superposition of true depth changes due to ocean currents, tides or stretching mooring lines, and the pressure sensor drift. After fitting a line to the pressure record, the trends in time and pressure were compared. The amount of depth change which was not displayed by the pressure data fit was then interpreted as drift of the pressure sensor. In most cases the drift was towards higher pressure. In some data sets an offset remained after the drift and sound 

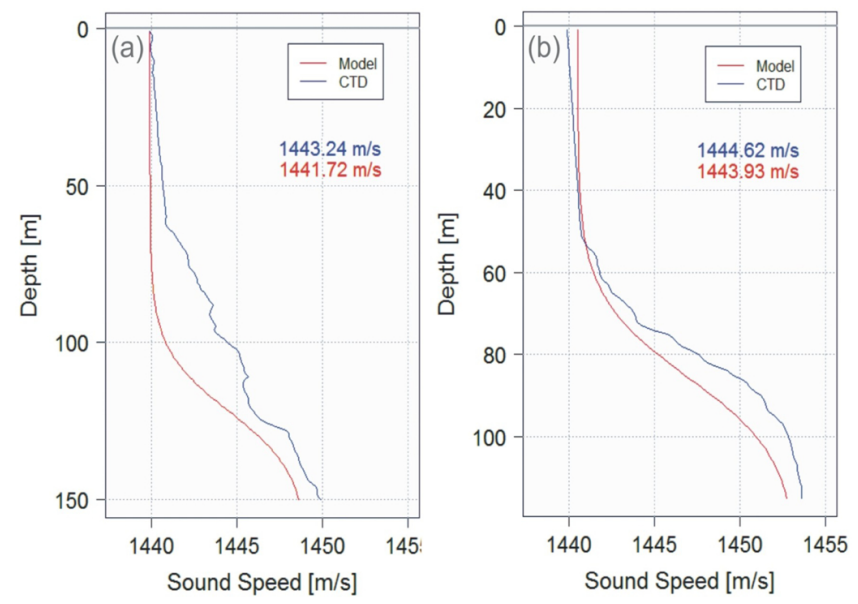

Figure 8. (a) Blue: vertical sound speed profile calculated from a CTD measurement on 16 December 2002 using the TEOS-10 Gibbs SeaWater Library (Wright et al., 2010). Red: the profile at the same time, calculated with the sound speed model using $T_{\text {uls }}$. The numbers are the vertical harmonic means of the profiles. The difference between both vertical averages of $1.52 \mathrm{~m} \mathrm{~s}^{-1}$ would cause an error in the ice draft of about $+16 \mathrm{~cm}$. (b) Vertical sound speed profiles on 13 July 2006. The difference between both vertical averages of $0.68 \mathrm{~m} \mathrm{~s}^{-1}$ would cause an error in the ice draft of about $+5 \mathrm{~cm}$.

speed corrections. Offsets could be easily corrected by levelling the upper bound of the ice draft echoes to zero draft. These offsets could not be explained by sound speed or sensor specifications and are believed to originate from instabilities or calibration errors in the pressure sensors.

\section{Winter ice draft error estimation}

The remaining error of the winter ice drafts corrected by the model was estimated in a similar manner as above, i.e.: the mean open water draft mode of identified leads was determined, and together with its standard deviation the rms-error was calculated. The number of identified leads in winter was about two thirds lower than in spring and autumn. The final winter rms-error was derived from the data sets AWI 2076, AWI 231-7, AWI 232-6, AWI 232-8 and AWI 233-2. It amounts to $\pm 23 \mathrm{~cm}$, where the mean open water draft mode is $20 \mathrm{~cm}$ and its standard deviation is $\pm 11 \mathrm{~cm}$. The value of $\pm 23 \mathrm{~cm}$ represents the measurement accuracy of the winter ice drafts corrected by the model.

To validate the accuracy of data corrected by the model, CTD profiles can be used to calculate a Gaussian error propagation by directly determining the uncertainty $\Delta c$. This can be achieved by comparing the CTD-derived vertical mean sound velocities to the model-derived sound velocities (Fig. 8). However, due to the lack of winter expeditions, only two winter CTD profiles are available directly on ULS positions with the ULS still moored: one on 13 July 2006, in a period of ice coverage at AWI 231-7 (Fig. 7), and one on 16 December 2002, in an open water period at AWI 232-5. The differences between the vertical profiles of mean sound velocities from CTD and the model are $1.52 \mathrm{~m} \mathrm{~s}^{-1}$ and $0.69 \mathrm{~m} \mathrm{~s}^{-1}$. The standard deviation of the two differences is $0.6 \mathrm{~m} \mathrm{~s}^{-1}$. To estimate the standard error of the mean from such a small sample size, the $t$ distribution has to be assumed (Schönwiese, 1992). The standard error can then be calculated by

$\Delta c=1.84 \frac{0.6 \mathrm{~m} \mathrm{~s}^{-1}}{\sqrt{2}}$,

where 1.84 is the correction factor from the $t$ distribution for $n=2$. Calculating an error propagation for the ULS equation using $\Delta c=0.78 \mathrm{~m} \mathrm{~s}^{-1}$ and the uncertainties $\Delta p, \Delta p_{\mathrm{a}}, \Delta t$ and $\Delta \alpha$ described above ( $\Delta \rho$ neglected), yields a standard error of $\Delta d= \pm 22 \mathrm{~cm}$, which almost matches the value found by lead detection. About $89 \%$ of this error is due to the pressure sensor uncertainties and about $9 \%$ due to the uncertainty of the sound velocity. The worst case error is $34 \mathrm{~cm}$. If the uncertainty in the density is included as $\Delta \rho=0.05 \mathrm{~kg} \mathrm{~m}^{-3}$ (Fig. 5), the Gaussian law of error propagation has to be extended (Gränicher, 1996) by a correlation term between $c$ and $\rho$, as these quantities are not independent of each other. The correlation coefficient in the term for $c$ and $\rho$ is about 0.95 , as determined from 60 CTD profiles. Including this term into the error propagation, the standard error would increase to $\pm 23 \mathrm{~cm}$, and the worst case error to $36 \mathrm{~cm}$. To obtain a larger sample $(n \gg 2)$ of differences between the modelled and CTD-derived sound speed, one can run the model with temperatures measured by CTD. In this case, $T_{\mathrm{uls}}$ is the CTD temperature at the depth level of the ULS. The obtained uncertainty $\Delta c$, using a set of $60 \mathrm{CTD}$ profiles, is nearly the same as estimated above $\left(0.75 \mathrm{~m} \mathrm{~s}^{-1}\right)$. This does not change the calculated error significantly.

For comparison, the winter ice drafts were also corrected by zero-line interpolation. The rms-error in this case is $\pm 14 \mathrm{~cm}$, with $3.8 \mathrm{~cm}$ mean open water draft mode and $\pm 13 \mathrm{~cm}$ standard deviation of the mean open water draft mode. If all leads detected by the search algorithm are additionally included in the estimation, the error is reduced to $\pm 12 \mathrm{~cm}$. In winter, the zero-line interpolation therefore results in a smaller statistical error compared to the model correction. On the other hand, the model correction has a stronger capability in correcting ice periods in which no open water occurs (Figs. 7 and 9). Note also that the error estimation is based on the detection of leads and that the error in Fig. 7 results from the absence of leads. The winter error estimation of $\pm 12 \mathrm{~cm}$ thus has to be considered as a minimum error. Both data versions are therefore provided with the files (except AWI 206-4, AWI 227-3, AWI-229 and AWI 230-2). A criterion for the selection between the two data types could be the evaluation of ice concentration data from passive microwave imagery. For times of low ice concentration the draft data corrected by the zero-level approach are expected to be more accurate. At times of high ice concentration the data 

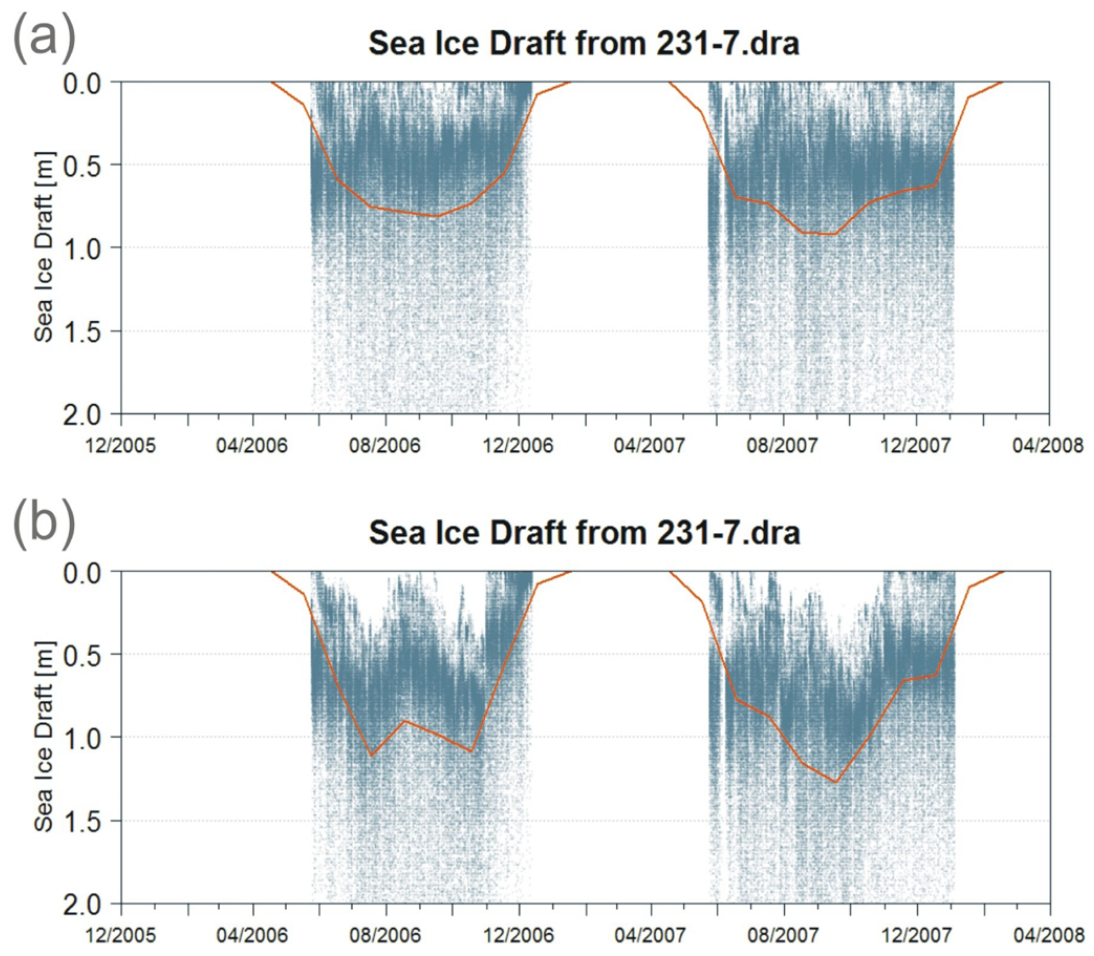

Figure 9. (a) Ice draft of AWI 231-7, corrected by zero-line interpolation. (b) The same ice draft, but with the months June-October corrected by the sound speed model (incl. pressure drift correction) and the remaining months by zero-line interpolation. The solid lines are monthly mean ice drafts.

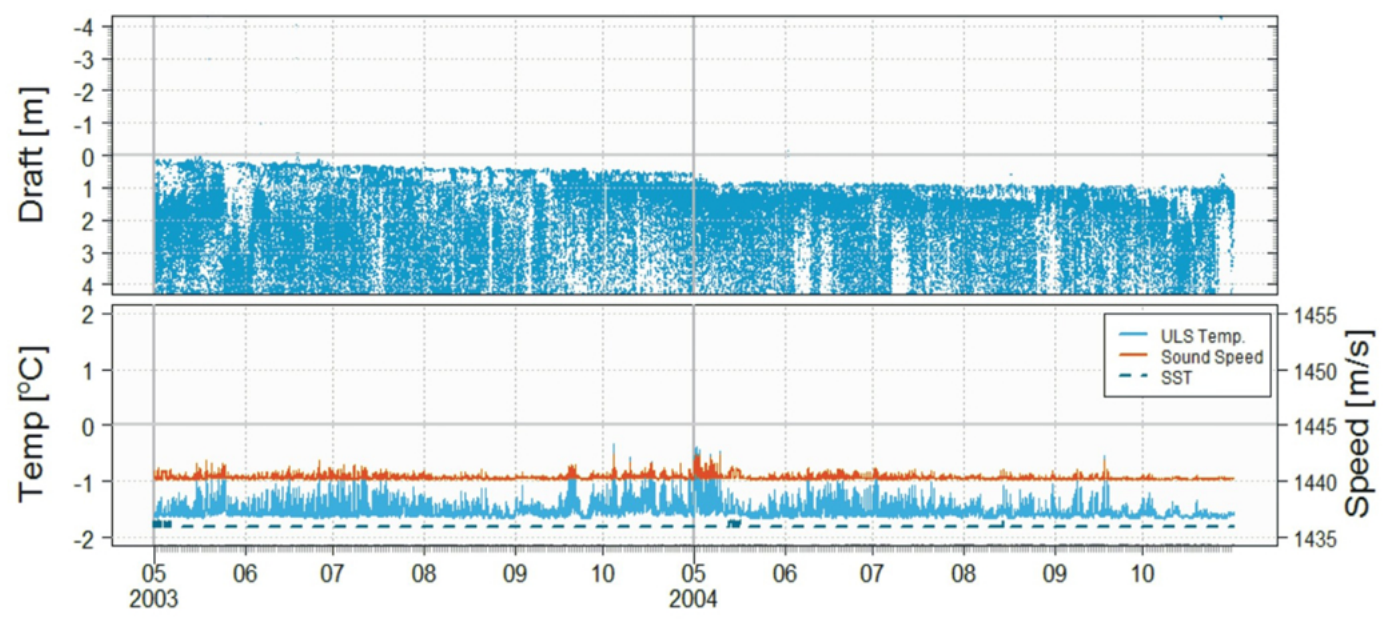

Figure 10. Upper panel: draft data of AWI 233-6 in the winters 2003 and 2004, corrected with the sound speed model. The effect of pressure drift is evident in the draft record. It results in an apparent change in ice draft of about $1 \mathrm{~m}$ over almost 1.5 yr. Lower panel: temperature at the ULS, sea surface temperature, and sound speed calculated with the model. Since the ULS temperature is always close to the freezing point, the vertical sound speed profile above the ULS is constant. This results in an almost constant vertical mean sound speed of about $1440 \mathrm{~m} \mathrm{~s}^{-1}$. The linear change in ice draft can therefore not be explained by changes in the sound velocity and is interpreted as pressure drift.

corrected by the model might be the better choice. For a more detailed analysis of the ULS accuracy the reader is referred to the work of Behrendt (2013).

\section{Systematic error}

Due to the size of the sonar footprint under the ice and the fact that the sonar echo is recorded when it passes a certain intensity threshold, ULS data are generally biased. The 


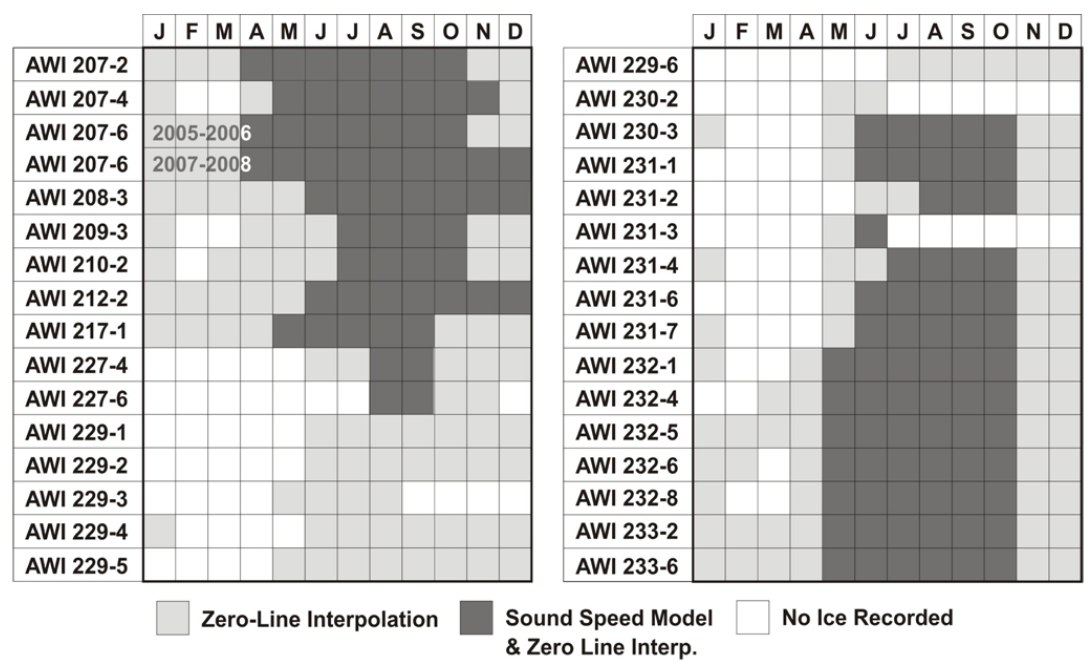

Figure 11. Periods of different ice draft correction in all available data sets. The winter months (dark colour) were identified by visually checking their draft values for possible leads. The winter months were corrected by the sound speed model and the zero-line interpolation (see text).

sonar footprint always contains ice types of different thickness, which leads to a skewed intensity distribution of each sonar echo. Assuming uniform reflectivity of the ice underside, the echo distribution is related to the ice thickness distribution within the sonar footprint. The statistical mode of the draft distribution is the most abundant thickness class of the ice and can therefore be regarded as the true ice thickness (Strass, 1998). The mode of the echo distribution is represented by the envelope voltage (Fig. 12).

However, for technical reasons the sonar signal is recorded before its amplitude reaches the mode of the echo intensity distribution. Hence, the ice draft is systematically overestimated, as the recorded signals stem from some of the deepest protruding points of the ice canopy. For a completely flat ice underside (i.e. level ice) the bias could be assumed to be zero. The technical influence on the bias could be reduced by taking the travel time when the peak value (envelope voltage) of the signal is reached or by reducing the opening angle of the sonar beam.

The bias may also be influenced by different geophysical situations. For example, it may occur when deep ridge keels enter the sonar beam. Normally, the sonar echoes are assumed to originate from ice above the central axis of the sonar beam. But echoes from ice keels at an off-axis position may arrive earlier at the ULS than echoes from the beam axis. If these signals exceed the detection threshold, the ice draft attributed to ice at the beam axis will be overestimated (Melling et al., 1995). This is not necessarily the case if the ice in the central axis is level ice, which on average has a much higher reflectivity than ridged ice (Melling, 1998). The bias may also vary over time, as it depends on ice thickness, the degree of ridging and the age of the ice. However, it is reduced by low sidelobes of the sonar beam pattern. A small

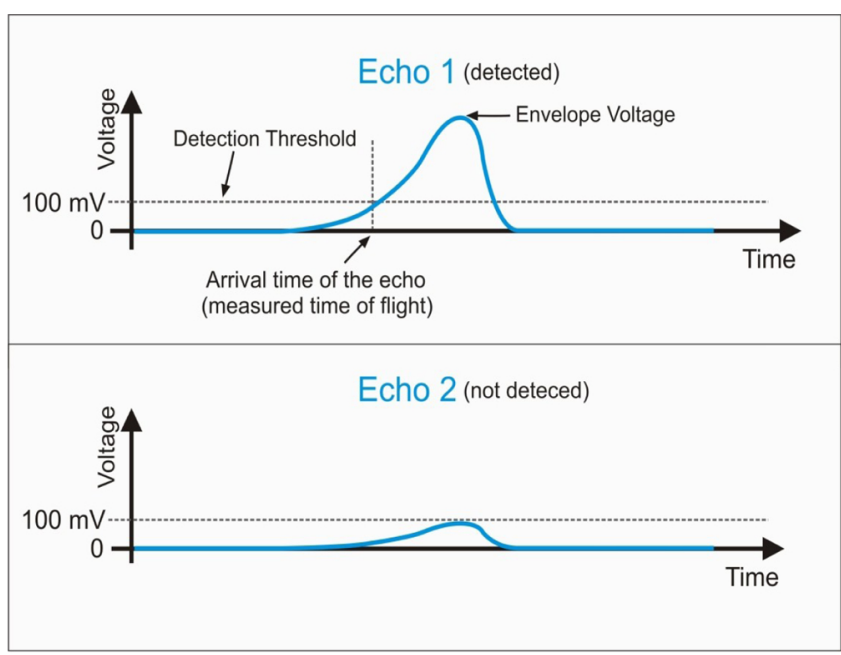

Figure 12. Detection of sonar signals and measurement threshold for the two-way travel time (time of flight). Top panel: example of a detected signal that passes the threshold of $100 \mathrm{mV}$. The arrival time of the echo is measured when the signal voltage equals $100 \mathrm{mV}$. Bottom panel: example of a weak signal that does not pass the detection threshold and hence is not recorded by the ULS.

variable bias may also be introduced by tides. Some pressure records of the ULS instruments show significant depth oscillations with amplitudes of up to $5 \mathrm{~m}$ due to semidiurnal and fortnightly tides. This periodically alters the size of the sonar footprint and thus the bias.

Strass (1998) estimated the bias by comparing the ice draft distributions to ice drafts from drillings in the Weddell Sea and obtained an overall mean value of $11.5 \%$. This compares to the value of $11.4 \%$, which can be derived from the results of Kvambekk and Vinje (1992) for an ice draft of $2.64 \mathrm{~m}$ 
Table 4. ULS biases calculated after Rothrock and Wensnahan (2007) for different ULS depths.

\begin{tabular}{llllllllll}
\hline Ice type & \multicolumn{10}{c}{ ULS depth } \\
\cline { 2 - 9 } & $100 \mathrm{~m}$ & $110 \mathrm{~m}$ & $120 \mathrm{~m}$ & $130 \mathrm{~m}$ & $140 \mathrm{~m}$ & $150 \mathrm{~m}$ & $160 \mathrm{~m}$ & $170 \mathrm{~m}$ & $180 \mathrm{~m}$ \\
\hline FY winter & $42 \mathrm{~cm}$ & $45 \mathrm{~cm}$ & $48 \mathrm{~cm}$ & $52 \mathrm{~cm}$ & $55 \mathrm{~cm}$ & $58 \mathrm{~cm}$ & $62 \mathrm{~cm}$ & $65 \mathrm{~cm}$ & $68 \mathrm{~cm}$ \\
MY winter & $42 \mathrm{~cm}$ & $44 \mathrm{~cm}$ & $47 \mathrm{~cm}$ & $49 \mathrm{~cm}$ & $52 \mathrm{~cm}$ & $54 \mathrm{~cm}$ & $56 \mathrm{~cm}$ & $59 \mathrm{~cm}$ & $61 \mathrm{~cm}$ \\
MY summer & $23 \mathrm{~cm}$ & $25 \mathrm{~cm}$ & $27 \mathrm{~cm}$ & $29 \mathrm{~cm}$ & $31 \mathrm{~cm}$ & $33 \mathrm{~cm}$ & $35 \mathrm{~cm}$ & $37 \mathrm{~cm}$ & $39 \mathrm{~cm}$ \\
\hline
\end{tabular}

$\mathrm{FY}=$ first-year ice, $\mathrm{MY}=$ multi-year ice

measured by a ULS with $5^{\circ}$ opening angle. From bias investigations in the Arctic one can also estimate a bias for the AWI ULS data. Johnsen (1989) used a scanning sonar with $1.7^{\circ}$ opening angle at a depth of $15 \mathrm{~m}$ under Arctic sea ice to map its bottom topography in different seasons at high resolution. Vinje et al. (1998) used this information to derive a bias as the difference between maximum draft and mean draft, depending on the footprint size and the ice type. Rothrock and Wensnahan (2007) fitted lines through these data and obtained the equation:

$d_{\max }-\bar{d}=a+[2 \cdot \tan (\alpha / 2)] b D_{T}$

for a sonar with an opening angle of $2^{\circ}$. Here, $d_{\max }$ is the deepest draft, $\bar{d}$ the mean draft, $D_{T}$ the ULS depth and the factors $a$ and $b$ depend on ice type and season (firstyear ice in winter: $a=0.08, b=0.077$, multiyear ice in winter: $a=0.18, b=0.055$, multiyear ice in summer: $a=0.04$, $b=0.044)$. The factor in the square brackets relates the footprint diameter to the ULS depth. For an opening angle of $2.5^{\circ}$ it is 0.044 . Using this value in Eq. (4) yields the bias values shown in Table 4.

A relative bias of $11.5 \%$ as given by Strass (1998) is obtained for a ULS at $150 \mathrm{~m}$ depth and a measured first-year winter ice draft of approximately $5 \mathrm{~m}$. However, Eq. (4) was obtained by measurements in the Arctic. The bias values in Table 4 are expected to be smaller in the Antarctic, as the sea ice is generally younger and less deformed than in the Northern Hemisphere (Haas, 2010). Note that the biases in Table 4 are based on a relation between the maximum and mean ice draft. The bias estimated by Strass (1998) for our ULS types is based on a relation between the draft mode and the measured draft which occurs when reaching the detection threshold of the ULS receiver. However, the difference between maximum draft and mean draft may be of similar magnitude as the difference between the threshold draft and the modal draft.

Overall, the bias results from the complex interplay determined by technical influences (i.e. the detection threshold and gain settings of the receiver), geophysical influences (i.e. sea ice age, geometry and scattering strength of the ice underside) and the sonar footprint size. The bias is therefore hard to quantify. The drillings used by Strass (1998) were made in the vicinity of the ULS positions, and they were grouped in order to approximate the ice conditions at the mooring sites
AWI-207, AWI-217, AWI-210 and AWI-212 in 1990-1992. This attempt showed that the relative bias may vary between 7.5 and $20 \%$ from region to region. However, the drillings do not represent the ice conditions on the other ULS positions, e.g. on the prime meridian. A large-scale drilling programme or measurements from electromagnetic induction (EM) sounding (Haas et al., 2008) on all ULS positions is yet not available. The bias is therefore not considered in the presented data and may be subtracted by the user, applying the above estimations. More detailed investigations of the ULS bias may become available in the near future, if large-scale EM surveys are conducted with a sufficiently high accuracy and spatial resolution.

\section{Selected results}

Results are presented for three ULS positions, two of them (AWI-207 and AWI-232) showing the most striking changes in sea ice thickness. The third record (AWI-231) is among the records with the largest amount of measured data. The upper panel in Fig. 13 shows the sea ice draft at AWI-207. The sea ice draft in the period 2006-2007 is on average more than one metre lower compared to the years 1996-1997, and almost three metres lower than in the year 1991 (Fig. 2). This pronounced negative trend is consistent with the general decrease of sea ice concentration in that region (Yuan and $\mathrm{Li}$, 2008). It is also noted that the sea ice season in 2007 started one month earlier than in the year 1997. The plots of AWI231 (Fig. 13, lower panel) indicate that the daily mean sea ice draft rarely exceeds $1 \mathrm{~m}$ in the region south of Maud Rise. The variability in the draft is lower compared to AWI-207. However, when comparing the years 2006 and 2007, it is obvious that the length of the ice season can vary significantly. Besides AWI-207, the other spot of pronounced changes in sea ice draft is AWI-232, at $0^{\circ}$ longitude on the continental slope (Fig. 2). Here, the sea ice draft shows a positive trend over the period 2000-2007 (Fig. 14). Whereas the maximum ice draft in 2000 is about $1.5 \mathrm{~m}$, the draft in 2007 reaches values of 4-5 m. Compared to the years 2003-2004 the end of the sea ice season occurs a few weeks later in the years $2007-$ 2008. This is consistent with the findings of Stammerjohn et al. (2012).

Generally, the thickest ice exists in the dynamic boundary regions of the Weddell Gyre (AWI-206, AWI-212, AWI-232 

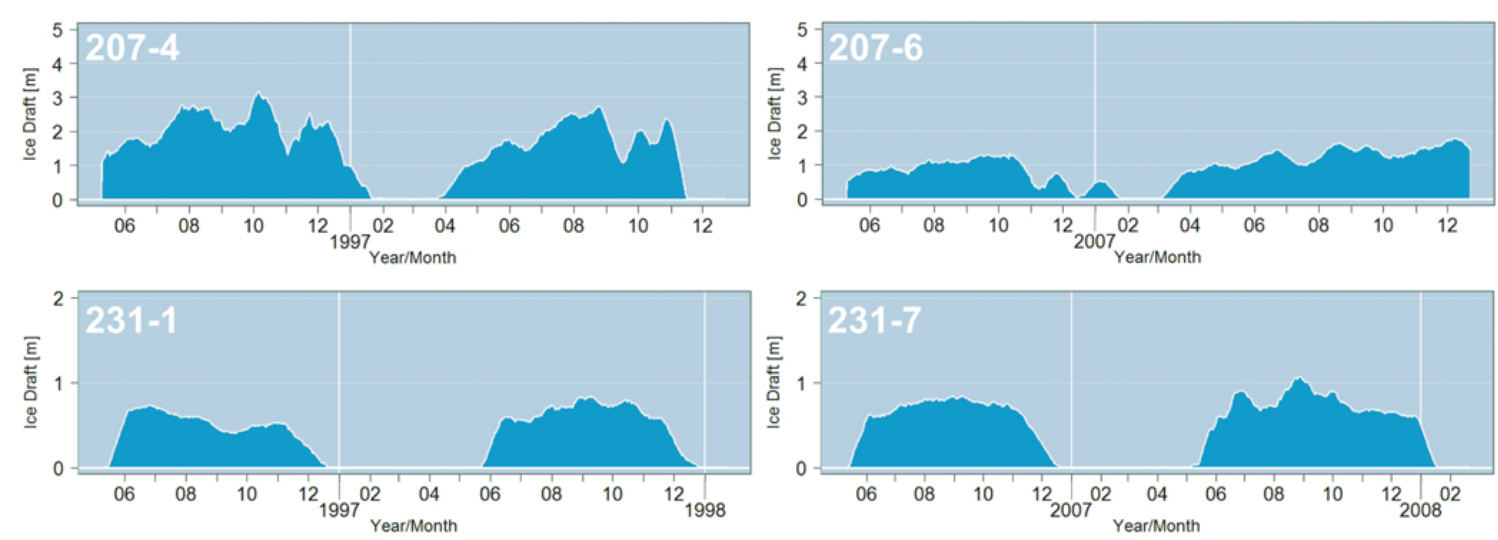

Figure 13. Selected 20-days running averages of daily mean sea ice draft. The dark blue area depicts the sea ice draft corrected by zero-line interpolation. Upper panel: sea ice draft on the position AWI-207, at the tip of the Antarctic Peninsula in the years 1996-1997 (AWI 207-4) and 2005-2008 (AWI 207-6). Lower panel: sea ice draft on the position AWI-231, southwest of Maud Rise in the years 1996-1997 (AWI 231-1) and 2006-2008 (AWI 231-7). For positions see Fig. 2.
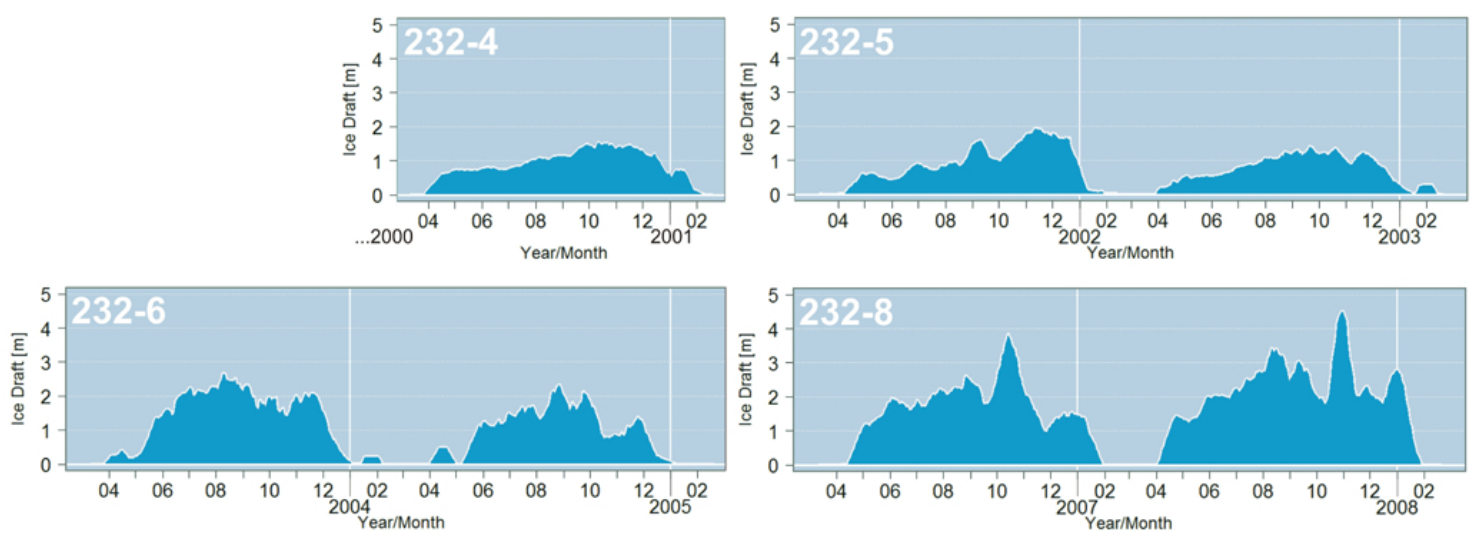

Figure 14. Same as in Fig. 13, but for sea ice draft at the position AWI-232 in the years 2000 (AWI 232-4), 2001-2002 (AWI 232-5), 2003-2004 (AWI 232-6) and 2006-2008 (AWI 232-8).

and AWI-233) (Fig. 2). Besides the trends discussed above, the ice draft at AWI-229 shows a negative trend in the period 2001-2005. A detailed analysis of the ULS data and the geophysical driving mechanisms for changes in the measured sea ice draft can be found in the work of Behrendt (2013).

\section{Conclusions}

Sea ice thickness is difficult to measure indirectly. However, among all available techniques upward looking sonars are still the most accurate tool to monitor the long-term evolution of sea ice thickness. The accuracy of ULS measurements is affected by errors in different parameters from which the distance between the ice-water interface and the sensor location is determined. As the distance is several orders of magnitude larger than typical ice drafts, small errors in the direct measurements (e.g. pressure uncertainty) or in the parameters needed to calculate the ice draft (e.g. sound velocity) cause comparably large errors in the draft estimates.
The draft data were corrected using two approaches. The first approach uses a correction line which is interpolated through leads present in the ice cover. Draft data corrected by this method were estimated to have an accuracy of $\pm 5 \mathrm{~cm}$ in spring and autumn and $\pm 12 \mathrm{~cm}$ in winter (see Fig. 11 for the respective months). The estimation was made by investigating the statistical properties of ice drafts in leads that were not captured by the correction line. As leads (serving as tie points for the correction line) are less frequent in the winter months, the winter drafts were alternatively corrected by a sound speed model. The model was developed on the basis of temperature data from ULS and CTD measurements and approximates the sound speed profile in the winter mixed layer. It could be shown that, in single cases, the model may have a better capability in correcting ice draft when no leads are present in the ice. However, the winter drafts corrected in this way have an accuracy of about $\pm 23 \mathrm{~cm}$. This empirical value was also estimated on the basis of lead identification and was confirmed by error propagation. 
Table 5. Available ULS data.

\begin{tabular}{|c|c|c|c|c|c|c|}
\hline File number & $\begin{array}{l}\text { Instrument } \\
\text { type }\end{array}$ & $\begin{array}{l}\text { Depth } \\
\text { [m] }\end{array}$ & $\begin{array}{l}\text { Sample rate } \\
\text { [min] }\end{array}$ & $\begin{array}{l}\text { Deployment } \\
\text { period }\end{array}$ & $\begin{array}{l}\text { Position } \\
\text { [lat, lon] }\end{array}$ & $\begin{array}{l}\text { Recorded } \\
\text { data }[\%]^{*}\end{array}$ \\
\hline AWI 206-4 & ES-300 V & 120 & 15 & 05/96-04/98 & $\begin{array}{l}63^{\circ} 29.6^{\prime} \mathrm{S}, \\
52^{\circ} 06.1^{\prime} \mathrm{W}\end{array}$ & 87 \\
\hline AWI 207-2 & ES-300 V & 140 & 8 & $11 / 90-11 / 92$ & $\begin{array}{l}63^{\circ} 45.1^{\prime} \mathrm{S}, \\
50^{\circ} 54.3^{\prime} \mathrm{W}\end{array}$ & 100 \\
\hline AWI 207-4 & ES-300 V & 180 & 15 & 05/96-04/98 & $\begin{array}{l}63^{\circ} 43.3^{\prime} \mathrm{S}, \\
50^{\circ} 49.2^{\prime} \mathrm{W}\end{array}$ & 75 \\
\hline AWI 207-6 & ES-300 VIII & 135 & 3 & 03/05-03/08 & $\begin{array}{l}63^{\circ} 42.2^{\prime} \mathrm{S}, \\
50^{\circ} 52.2^{\prime} \mathrm{W}\end{array}$ & 55 \\
\hline AWI 208-3 & ES-300 V & 115 & 4 & 01/93-01/95 & $\begin{array}{l}65^{\circ} 37.7^{\prime} \mathrm{S}, \\
36^{\circ} 29.4^{\prime} \mathrm{W}\end{array}$ & 76 \\
\hline AWI 209-3 & ES-300 V & 90 & 4 & $12 / 92-01 / 95$ & $\begin{array}{l}66^{\circ} 37.4^{\prime} \mathrm{S}, \\
27^{\circ} 07.2^{\prime} \mathrm{W}\end{array}$ & 42 \\
\hline AWI 210-2 & ES-300 V & 130 & 8 & $12 / 90-12 / 92$ & $\begin{array}{l}69^{\circ} 39.6^{\prime} \mathrm{S} \\
15^{\circ} 42.9^{\prime} \mathrm{W}\end{array}$ & 100 \\
\hline AWI 212-2 & ES-300 V & 130 & 8 & $12 / 90-12 / 92$ & $\begin{array}{l}70^{\circ} 54.7^{\prime} \mathrm{S}, \\
11^{\circ} 57.8^{\prime} \mathrm{W}\end{array}$ & 100 \\
\hline AWI 217-1 & ES-300 V & 115 & 8 & $11 / 90-11 / 92$ & $\begin{array}{l}64^{\circ} 25.1^{\prime} \mathrm{S} \\
45^{\circ} 51.0^{\prime} \mathrm{W}\end{array}$ & 100 \\
\hline AWI 227-3 & ES-300 V & 144 & 8 & 04/96-01/97 & $\begin{array}{l}59^{\circ} 01.8^{\prime} \mathrm{S} \\
00^{\circ} 00.0^{\prime} \mathrm{W}\end{array}$ & 90 \\
\hline AWI 227-4 & ES-300 VI & 135 & 3 & 01/97-05/98 & $\begin{array}{l}59^{\circ} 04.3^{\prime} \mathrm{S} \\
00^{\circ} 01.3^{\prime} \mathrm{E}\end{array}$ & 93 \\
\hline AWI 227-6 & ES-300 VIII & 140 & 8 & 03/99-12/00 & $\begin{array}{l}59^{\circ} 04.2^{\prime} \mathrm{S} \\
00^{\circ} 04.4^{\prime} \mathrm{E}\end{array}$ & 99 \\
\hline AWI 229-1 & ES-300 V & 160 & 15 & 04/96-05/98 & $\begin{array}{l}63^{\circ} 59.6^{\prime} \mathrm{S} \\
00^{\circ} 00.3^{\prime} \mathrm{W}\end{array}$ & 72 \\
\hline AWI 229-2 & ES-300 VIII & 150 & 4 & 05/98-03/99 & $\begin{array}{l}63^{\circ} 58.5^{\prime} \mathrm{S} \\
00^{\circ} 04.6^{\prime} \mathrm{W}\end{array}$ & 93 \\
\hline AWI 229-3 & ES-300 V & 120 & 4 & 03/99-12/00 & $\begin{array}{l}63^{\circ} 57.8^{\prime} \mathrm{S} \\
00^{\circ} 02.3^{\prime} \mathrm{E}\end{array}$ & 22 \\
\hline AWI 229-4 & $\mathrm{ES}-300 \mathrm{~V}$ & 130 & 4 & $12 / 00-12 / 02$ & $\begin{array}{l}63^{\circ} 57.9^{\prime} \mathrm{S} \\
00^{\circ} 02.4^{\prime} \mathrm{E}\end{array}$ & 81 \\
\hline AWI 229-5 & ES-300 VIII & 120 & 4 & $12 / 02-02 / 05$ & $\begin{array}{l}63^{\circ} 57.2^{\prime} \mathrm{S} \\
00^{\circ} 00.2^{\prime} \mathrm{W}\end{array}$ & 98 \\
\hline AWI 229-6 & ES-300 VIII & 150 & 1 & $02 / 05-12 / 05$ & $\begin{array}{l}63^{\circ} 57.2^{\prime} \mathrm{S} \\
00^{\circ} 00.4^{\prime} \mathrm{W}\end{array}$ & 76 \\
\hline AWI 230-2 & ES-300 V & 150 & 4 & 01/99-12/00 & $\begin{array}{l}66^{\circ} 00.3^{\prime} \mathrm{S} \\
00^{\circ} 10.6^{\prime} \mathrm{W}\end{array}$ & 23 \\
\hline AWI $230-3$ & ES-300 VI & 190 & 4 & $12 / 00-12 / 02$ & $\begin{array}{l}66^{\circ} 00.3^{\prime} \mathrm{S} \\
00^{\circ} 10.4^{\prime} \mathrm{E}\end{array}$ & 100 \\
\hline AWI 231-1 & ES-300 V & 165 & 15 & 04/96-05/98 & $\begin{array}{l}66^{\circ} 30.0^{\prime} \mathrm{S} \\
00^{\circ} 00.4^{\prime} \mathrm{W}\end{array}$ & 77 \\
\hline AWI 231-2 & ES-300 VIII & 180 & 4 & 05/98-01/99 & $\begin{array}{l}66^{\circ} 30.06^{\prime} \mathrm{S}, \\
00^{\circ} 01.1^{\prime} \mathrm{W}\end{array}$ & 97 \\
\hline AWI 231-3 & ES-300 V & 100 & 4 & 01/99-12/00 & $\begin{array}{l}66^{\circ} 29.9^{\prime} \mathrm{S} \\
00^{\circ} 00.9^{\prime} \mathrm{W}\end{array}$ & 23 \\
\hline AWI 231-4 & ES-300 VIII & 185 & 4 & $12 / 00-12 / 02$ & $\begin{array}{l}66^{\circ} 30.0^{\prime} \mathrm{S} \\
00^{\circ} 01.8^{\prime} \mathrm{W}\end{array}$ & 98 \\
\hline AWI 231-6 & ES-300 VIII & 145 & 1 & $02 / 05-12 / 05$ & $\begin{array}{l}66^{\circ} 30.7^{\prime} \mathrm{S}, \\
00^{\circ} 01.9^{\prime} \mathrm{W}\end{array}$ & 97 \\
\hline AWI 231-7 & ES-300 VIII & 125 & 2 & $12 / 05-03 / 08$ & $\begin{array}{l}66^{\circ} 30.7^{\prime} \mathrm{S} \\
00^{\circ} 01.9^{\prime} \mathrm{W}\end{array}$ & 62 \\
\hline
\end{tabular}


Table 5. Continued.

\begin{tabular}{|c|c|c|c|c|c|c|}
\hline File number & $\begin{array}{l}\text { Instrument } \\
\text { type }\end{array}$ & $\begin{array}{l}\text { Depth } \\
{[\mathrm{m}]}\end{array}$ & $\begin{array}{l}\text { Sample rate } \\
\text { [min] }\end{array}$ & $\begin{array}{l}\text { Deployment } \\
\text { period }\end{array}$ & $\begin{array}{l}\text { Position } \\
\text { [lat, lon] }\end{array}$ & $\begin{array}{l}\text { Recorded } \\
\text { data }[\%]^{*}\end{array}$ \\
\hline AWI 232-1 & $\mathrm{ES}-300 \mathrm{~V}$ & 100 & 15 & 04/96-02/97 & $\begin{array}{l}69^{\circ} 00.0^{\prime} \mathrm{S} \\
00^{\circ} 00.0^{\prime} \mathrm{W}\end{array}$ & 97 \\
\hline AWI 232-4 & ES-300 VI & 160 & 4 & 01/99-12/00 & $\begin{array}{l}68^{\circ} 59.7^{\prime} \mathrm{S} \\
00^{\circ} 01.9^{\prime} \mathrm{E}\end{array}$ & 65 \\
\hline AWI 232-5 & ES-300 VIII & 160 & 4 & $12 / 00-12 / 02$ & $\begin{array}{l}68^{\circ} 59.5^{\prime} \mathrm{S} \\
00^{\circ} 02.2^{\prime} \mathrm{W}\end{array}$ & 96 \\
\hline AWI 232-6 & ES-300 VIII & 160 & 4 & $12 / 02-02 / 05$ & $\begin{array}{l}68^{\circ} 59.9^{\prime} \mathrm{S} \\
00^{\circ} 00.3^{\prime} \mathrm{W}\end{array}$ & 100 \\
\hline AWI 232-8 & ES-300 VIII & 140 & 2 & $12 / 05-03 / 08$ & $\begin{array}{l}68^{\circ} 59.8^{\prime} \mathrm{S} \\
00^{\circ} 00.1^{\prime} \mathrm{W}\end{array}$ & 62 \\
\hline AWI 233-2 & ES-300 VI & 110 & 3 & 02/97-04/98 & $\begin{array}{l}69^{\circ} 24.2^{\prime} \mathrm{S} \\
00^{\circ} 00.0^{\prime} \mathrm{E}\end{array}$ & 90 \\
\hline AWI 233-6 & ES-300 VIII & 180 & 4 & $12 / 02-02 / 05$ & $\begin{array}{l}69^{\circ} 23.7^{\prime} \mathrm{S}, \\
00^{\circ} 04.0^{\prime} \mathrm{W}\end{array}$ & 98 \\
\hline
\end{tabular}

${ }^{*}$ Relative to full deployment period.

The sound speed model therefore needs to be further improved. This could be achieved by investigating a possible bias in the differences between CTD-derived sound speeds and the model-derived sound speeds. Also the refinement in the relation between the model parameters could be promising. The strength of the sound speed correction could also be improved by deploying more ULS instruments at depths of around $100 \mathrm{~m}$ or in areas where the winter sound speed profiles are constant. This would bypass the problem with the variable thermocline depth and increase the quality of the winter ice draft measurements. Only in regions where large icebergs are frequent should the ULS instruments be operated at larger depths. It is also recommended to conduct more CTD measurements during ice coverage in the future. This would significantly improve the quality control of sound speed models and also the estimations of $\Delta c$. With the increasing availability of winter data under the ice from profiling floats the situation is expected to improve significantly.

To reduce the uncertainty of the ULS bias, further comprehensive field work is needed. More Antarctic ice thickness data, e.g. from EM surveys or high-resolution sonar measurements of the underside topography, are needed for a thorough estimation. An alternative way could be simulations which include all geophysical and technical effects that influence the bias. For the above reasons, a bias was not subtracted from the ULS data published in the PANGAEA archive.

A problem with the presented ULS data is the lack of ice drift information. Contrary to the measurements reported by Melling et al. (1995), the AWI ULS instruments were deployed without acoustic Doppler current profilers (ADCP). Their data can therefore not be converted into space-referenced data. Ice draft distributions of timereferenced data may contain peaks different from the distributions of space-referenced data (Melling et al., 1995). This sampling problem is induced by the character of the ice drift. If, by chance, only thick ice classes are present when the ice drift is slow, these classes will be more common in the draft statistics. The differences between the two distributions are expected to decrease in daily or even more in monthly mean sea ice drafts. However, the conversion of the observations into regular intervals of space would eliminate the problem.

The main findings presented in Sect. 11 indicate that the sea ice thickness undergoes distinct changes at the Antarctic Peninsula and on the prime meridian. The ice in the peninsula region shows a pronounced thinning of about $2 \mathrm{~m}$ between 1991 and 2007. A thinning could also be observed in the northeastern Weddell Sea (north of the Maud Rise sea mount) in the period 2001-2005. The sea ice near the coast in the eastern Weddell Sea on the contrary shows a positive thickness trend over the period 2000-2007. A positive trend in ice thickness could also be observed south of Maud Rise during 2005-2007.

Despite its weaknesses in reproducing ice draft in austral winter, the presented data product will serve an important validation tool for satellite algorithms and sea ice models.

Acknowledgements. This work occurred in the context of the project "The Sea Ice Thickness in the Atlantic Sector of the Southern Ocean" (FA 436/3-1 and FA 436/3-2) in the framework of the priority programme "Antarctic Research with Comparative Studies in Arctic Polar Regions" (SPP 1158) supported by the Deutsche Forschungsgemeinschaft (DFG). We also thank the anonymous referee and Giorgio Budillon for helping us to improve the quality of our paper.

Edited by: G. M. R. Manzella 


\section{References}

Ackley, S., Wadhams, P., Comiso, J. C. and Worby, A. P.: Decadal decrease of Antarctic sea ice extent inferred from whaling records revisited on the basis of historical and modern sea ice records, Polar Res., 22, 19-25, 2003.

Behrendt, A.: The Sea Ice Thickness in the Atlantic Sector of the Southern Ocean, Ph.D. thesis, University of Bremen, Germany, 239 pp., 2013.

Cavalieri, D. J. and Parkinson, C. L.: Antarctic sea ice variability and trends, 1979-2006, J. Geophys. Res., 113, C07004, doi:10.1029/2007JC004564, 2008.

Curran, M. A. J., van Ommen, T. D., Morgan, V. I., Phillips, K. L., and Palmer, A. S.: Ice Core Evidence for Antarctic Sea Ice Decline Since the 1950s, Science, 302, 1203-1206, 2003.

Dieckmann, G. S. and Hellmer, H. H.: The Importance of Sea Ice: An Overview, in: Sea Ice, 2, edited by: Thomas, D. N. and Dieckmann, G. S., Wiley-Blackwell, 1-22, 2010.

Gränicher, H.: Messung beendet - was nun?, 2, vdf Hochschulverlag, Zürich, 1996.

Haas, C.: Dynamics versus Thermodynamics: The Sea Ice Thickness Distribution, in: Sea Ice, 2, edited by: Thomas, D. N. and Dieckmann, G. S., Wiley-Blackwell, 113-151, 2010.

Haas, C., Nicolaus, M., Willmes, S., Worby, A., and Flinspach, D.: Sea ice and snow thickness and physical properties of an ice floe in the western Weddell Sea and their changes during spring warming, Deep-Sea Res. Pt. II, 55, 963-974, doi:10.1016/j.dsr2.2007.12.020, 2008.

Harms, S., Fahrbach, E., and Strass, V. H.: Sea ice transports in the Weddell Sea, J. Geophys. Res., 106, 9057-9073, 2001.

Hauck, W. W., Koch, W., Abernethy, D. and Williams, R. L.: Making Sense of Trueness, Precision, Accuracy, and Uncertainty, Pharmacopeial Forum, 34, 838-842, 2008.

Honeywell: Pressure Transducer Accuracy in Application, Technical Note, Honeywell International Inc., Freeport (Illinois), 2004.

Johnsen, A. S.: Relation between top and bottom ice topography using scanning sonar, in: Proceedings of the Tenth International Conference on Port and Ocean Engineering Under Arctic Conditions, Luleå Univ. of Technol., Luleå, Sweden, 12-16 June, 1989.

King, J. C.: Validation of ECMWF Sea Level Pressure Analyses over the Bellingshausen Sea, Antarctica, Weather Forecast., 18, 536-540, 2003.

Kuhlbrodt, T., Griesel, A., Montoya, M., Levermann, A., Hofmann, M., and Rahmstorf, S.: On the driving processes of the Atlantic meridional overturning circulation, Rev. Geophys., 45, doi:10.1029/2004RG000166, 2007.

Kvambekk, A. S. and Vinje, T.: Ice draft recordings from upward looking sonars (ULSs) in the Fram Strait and the Barents Sea in 1987/88 and 1990/91, Norsk Polarinstitutt Rapportserie, 79, p. 16, Oslo, Norway, 1992.

Lemke, P., Ren, J., Alley, R. B., Allison, I., Carrasco, J., Flato, G., Fujii, Y., Kaser, G., Mote, P., Thomas, R. H., and Zhang, T.: Observations: Changes in Snow, Ice and Frozen Ground, in: Climate Change 2007: The Physical Science Basis. Contribution of Working Group I to the Fourth Assessment Report of the Intergovernmental Panel on Climate Change, edited by: Solomon, S., Qin, D., Manning, M., Chen, Z., Marquis, M., Averyt, K. B., Tignor, M., and Miller, H. L., Cambridge University Press, Cambridge, United Kingdom and New York, NY, USA, 2007.
Lothe, T. and Baker, A.: Processing of Data from ES 300 Upward Looking Sonars, A guide to data conversion and processing, CMR Report, Ref. Nr.: CMR-00-A10031, Bergen, Norway, 2000.

Mackenzie, K. V.: Nine-term equation for sound speed in the oceans, J. Acoust. Soc. Am., 70, 807-812, 1981.

Melling, H.: Sound Scattering from Sea Ice: Aspects Relevant to Ice-Draft Profiling by Sonar, J. Atmos. Ocean. Tech., 15, 10231034, 1998.

Melling, H., Johnston, P. H., and Riedel, D. A.: Measurements of the Topography of Sea Ice by Moored Subsea Sonar, J. Atmos. Ocean. Tech., 12, 589-602, 1995.

Melling, H. and Riedel, D. A.: The underside topography of sea ice over the continental shelf of the Beaufort Sea in the winter of 1990, J. Geophys. Res., 100, 13641-13653, 1995.

Parkinson, C. L. and Cavalieri, D. J.: Antarctic sea ice variability and trends, 1979-2010, The Cryosphere, 6, 871-880, doi:10.5194/tc-6-871-2012, 2012.

Roedel, W.: Physik unserer Umwelt - Die Atmosphäre, 2, Springer, 1994.

Rothrock, D. A. and Wensnahan, M.: The Accuracy of Sea Ice Drafts Measured from U.S. Navy Submarines, J. Atmos. Ocean. Tech., 24, 1936-1949, doi:10.1175/JTECH2097.1, 2007.

Rothrock, D. A., Percival, D. B., and Wensnahan, M.: The decline in arctic sea-ice thickness: Separating the spatial, annual, and interannual variability in a quarter century of submarine data, J. Geophys. Res., 113, C05003, doi:10.1029/2007JC004252, 2008.

Schönwiese, C. D.: Praktische Statistik für Meteorologen und Geowissenschaftler, 2, Gebrüder Borntraeger, Berlin/Stuttgart, 1992.

Stammerjohn, S., Massom, R., Rind, D., and Martinson, D.: Regions of rapid sea ice change: An interhemispheric seasonal comparison, Geophys. Res. Lett., 39, L06501, doi:10.1029/2012GL050874, 2012.

Strass, V. H.: Measuring sea ice draft and coverage with moored upward looking sonars, Deep-Sea Res. Pt. I, 45, 795-818, 1998.

Thomas, D. N. and Dieckmann, G. S.: Antarctic Sea Ice - a Habitat for Extremophiles, Science, 295, 641-644, doi:10.1126/science.1063391, 2002.

Vinje, T., Nordlund, N., and Kvambekk, A.: Monitoring ice thickness in Fram Strait, J. Geophys. Res., 103, 10437-10449, 1998.

Wadhams, P. and Davis, N. R.: Further evidence of ice thinning in the Arctic Ocean, Geophys. Res. Lett., 27, 3973-3975, 2000.

Whitworth III, T. and Nowlin Jr., W. D.: Water Masses and Currents of the Southern Ocean at the Greenwich Meridian, J. Geophys. Res., 92, 6462-6476, 1987.

Worby, A. P. and Comiso, J. C.: Studies of the Antarctic sea ice edge and ice extent from satellite and ship observations, Remote Sens. Environ., 92, 98-111, doi:10.1016/j.rse.2004.05.007, 2004.

Wright, D. G., Feistel, R., Reissmann, J. H., Miyagawa, K., Jackett, D. R., Wagner, W., Overhoff, U., Guder, C., Feistel, A., and Marion, G. M.: Numerical implementation and oceanographic application of the thermodynamic potentials of liquid water, water vapour, ice, seawater and humid air - Part 2: The library routines, Ocean Sci., 6, 695-718, doi:10.5194/os-6-695-2010, 2010.

Yuan, X. and Li, C.: Climate modes in southern high latitudes and their impacts on Antarctic sea ice, J. Geophys. Res., 113, C06S91, doi:10.1029/2006JC004067, 2008. 
Zwally, H. J., Yi, D., Kwok, R., and Zhao, Y.: ICESat measurements of sea ice freeboard and estimates of sea ice thickness in the Weddell Sea, J. Geophys. Res., 113, C02S15, doi:10.1029/2007JC004284, 2008. 